\title{
Mindfulness-induced selflessness: a MEG neurophenomenological study
}

\author{
Yair Dor-Ziderman 1*, Aviva Berkovich-Ohana2 ${ }^{2}$ Joseph Glicksohn ${ }^{1,3}$ and Abraham Goldstein ${ }^{1,4}$ \\ The Leslie and Susan Gonda (Goldschmied) Multidisciplinary Brain Research Center, Bar-Ilan University, Ramat Gan, Israel \\ ${ }^{2}$ Department of Neurobiology, Weizmann Institute of Science, Rehovot, Israel \\ ${ }^{3}$ Department of Criminology, Bar-llan University, Ramat Gan, Israel \\ ${ }^{4}$ Department of Psychology, Bar-llan University, Ramat Gan, Israel
}

\section{Edited by:}

Wendy Hasenkamp, Mind and Life

Institute, USA

\section{Reviewed by:}

Brenton W. McMenamin, University of Maryland, USA

Norman Farb, Baycrest, Canada

\section{*Correspondence:}

Yair Dor-Ziderman, Electromagnetic

Brain Imaging Unit, The Leslie and

Susan Gonda (Goldschmied)

Multidisciplinary Brain Research

Center, Bar-Ilan University, Building

number 901, Ramat Gan 52900,

Israel

e-mail:yairem@gmail.com
Contemporary philosophical and neurocognitive studies of the self have dissociated two distinct types of self-awareness: a "narrative" self-awareness (NS) weaving together episodic memory, future planning and self-evaluation into a coherent self-narrative and identity, and a "minimal" self-awareness (MS) focused on present momentary experience and closely tied to the sense of agency and ownership. Long-term Buddhist meditation practice aims at realization of a "selfless" mode of awareness (SL), where identification with a static sense of self is replaced by identification with the phenomenon of experiencing itself. NS-mediating mechanisms have been explored by neuroimaging, mainly $\mathrm{fMRI}$, implicating prefrontal midline structures, but MS processes are not well characterized and SL even less so. To this end we tested 12 long-term mindfulness meditators using a neurophenomenological study design, incorporating both magnetoencephalogram (MEG) recordings and first person descriptions. We found that (1) NS attenuation involves extensive frontal, and medial prefrontal gamma band $(60-80 \mathrm{~Hz})$ power decreases, consistent with $\mathrm{fMRI}$ and intracranial EEG findings; (2) MS attenuation is related to beta-band $(13-25 \mathrm{~Hz})$ power decreases in a network that includes ventral medial prefrontal, medial posterior and lateral parietal regions; and (3) the experience of selflessness is linked to attenuation of beta-band activity in the right inferior parietal lobule. These results highlight the role of dissociable frequency-dependent networks in supporting different modes of self-processing, and the utility of combining phenomenology, mindfulness training and electrophysiological neuroimaging for characterizing self-awareness.

Keywords: self-awareness, minimal self, narrative self, MEG, mindfulness meditation, neurophenomenology, beta frequency band, right inferior parietal lobule

\section{INTRODUCTION}

An unremitting companion of human experience is the sense of self. Amidst the ocean of coming-and-going waves of perceptions, cognitions and emotions, an absolute certainty regarding the identity of the present-moment experiencer- "self as I"remains unwavering (James, 1890). On the other hand, the thread of a constant, static, unchanging self-the "self as Me"-stretches back to childhood years, and extends as far into the future as one can imagine. The protagonist of both scenarios is experienced as one-and-the-same, even though the respective (imagined/remembered) bodies, mental capacities, as well as external contexts have completely changed. These phenomenally distinct aspects of self-awareness are being re-conceptualized by contemporary philosophers, psychologists and neurobiologists, aiming at a fruitful exchange between philosophy of mind, phenomenology, and the cognitive sciences. One such influential conceptualization has been offered by Gallagher (2000) as "minimal" and "narrative" forms of self-awareness.

The "minimal" self (MS) is defined as a consciousness of oneself as the immediate subject of experience. It is pre-reflective, present-centered, experiential in nature, and importantly, involves a sense of "ownership" and "agency": the sense that it is I who is undergoing an experience (Gallagher, 2000). MS, or "core self" in Damasio's $(1999,2010)$ terms, is understood to be intermittent. Damasio describes it as "... a transient entity, ceaselessly recreated for each and every object with which the brain interacts" (Damasio, 1999, p. 17), in this way implementing a self/non-self distinction and thus specifying the self in perception, cognition, emotion, and action (Christoff et al., 2011). The "narrative" self (NS), on the other hand, refers to a self extended in time, heavily reliant on language, episodic/autobiographical memory and imagination (planned/expected future), and corresponding to identity and personhood. The notion of NS has appeared in the literature under other names such as the "extended" self and "conceptual" self (Neisser, 1988), the "autonoetic" self (Gardiner, 2001) and the "autobiographical" self (Damasio, 1999, 2010), and has been shown to be closely tied to a neurophysiological baseline (Gusnard et al., 2001; Buckner et al., 2008), the so-called defaultmode network (DMN, Gusnard and Raichle, 2001; Raichle et al., 
2001) and to mind-wandering (Mason et al., 2007; Christoff et al., 2009; Hasenkamp et al., 2012). It is important to note that NS and MS are processes which may operate concurrently. Like other conscious mental content produced by the brain, NS representations, perceived as thoughts and feelings, are stamped with the subjective signature of being our thoughts and feelings. Thus, selfspecifying processes are at play also during NS (Gallagher, 2000; Damasio, 2010).

Eastern philosophy, and in particular Buddhist philosophy, exhibits a radically different view of the self and personal identity, advocating a "selfless" mode of processing phenomena (SL). At the core of Buddhist psychology lies the teaching of there being no such thing as a permanent, unchanging self (Dreyfus and Thompson, 2007; Olendzki, 2010). The self is understood to be illusory in the sense of being no more than a mental process-and identification with it is understood to be at the very root of suffering. Thus, a primary target of Buddhist practice is the realization of the illusory nature of the self and cultivation of a selfless, boundless mode of experience where identification with a static sense of self is replaced by identification with the phenomenon of experiencing itself (Hart, 1987; Dalai Lama, 1991; Austin, 2000; Ekman et al., 2005; Wallace, 2006; Nydahl, 2008). The notion of relinquishing the sense of owning and directing experience, may seem to the Western mind as nothing short of pathological (for a related discussion, see Engler, 2003). And indeed, pathological brains such as of schizophrenic patients experiencing "thought insertion" (Frith, 1992; Gallagher, 2004) or patients who have suffered lesions (Damasio et al., 2012; Philippi et al., 2012) compromising specific self functions, have largely contributed to Damasio's and Gallagher's understanding of the minimal/core self-concept. In a similar vein, as has been previously suggested (Lutz et al., 2007; Tagini and Raffone, 2010), long-term mindfulness meditators can provide parallel information regarding the self through diminishing the agentive/ownership aspects of present-moment experience. Such information, however, has the advantage of being volitionally produced and in non-diseased brains.

The neurophysiology of NS is relatively well established. A wealth of recent large-scale meta-analyses of mainly fMRI studies investigating self-referential processing through a variety of paradigms have consistently shown it to be modulated by a subset of the DMN, namely the central midline structures, and in particular the medial prefrontal cortex (mPFC) (Northoff et al., 2006, 2011; Buckner et al., 2008; Andrews-Hanna et al., 2010; Qin and Northoff, 2011; Whitfield-Gabrieli et al., 2011; Kim, 2012). Translating these findings into electrophysiological terms, there is accumulating evidence that the fMRI's hemodynamic response signal attributed to DMN and self-referential processing is correlated with neuronal activity in the gamma band (EEG studies-Mantini et al., 2007; Berkovich-Ohana et al., 2012), and in particular high-gamma band (intracranial EEG studies-Nir et al., 2007; Jerbi et al., 2010; Ossandón et al., 2011; Ramot et al., 2012). It should be noted that whether self-referential paradigms can reveal neural activity specific to the self is a matter of current debate, as these tasks involve, and are thus confounded by, higher-order cognitive functions such as evaluation, judgment and reflective thought (Legrand and Ruby, 2009; Christoff et al., 2011; Northoff et al., 2011).

The neural correlates of MS are less well established, with approaches aiming at identifying self-specifying pre/nonreflective processes including merely perceiving, without judgment or evaluation, self-specific vs. non-specific stimuli (Schneider et al., 2008; Northoff et al., 2009), or improving time resolution using event-related EEG (Esslen et al., 2008) or MEG (Walla et al., 2007). Other approaches are informed by phenomenology (Gallagher and Sørensen, 2006) and target MS via one of its core attributes - the sense of agency and ownership (for reviews see David et al., 2008; Sperduti et al., 2011). Key regions here include the inferior parietal lobule (IPL) and the insula. Importantly, the literature does not supply information regarding the oscillatory signature of these mostly fMRI findings. Oscillatory power increases/decreases that occur in specific frequency bands and within different cortical areas have been shown to be functionally relevant in the brain (Singh, 2012). In particular, the different modes of self-awareness might not only involve different brain topographies, but perhaps also different oscillatory signatures. In this regard, MEG is an appealing research tool as it has both an excellent temporal (and thus spectral) resolution, and it allows for a reliable source reconstruction (relative to EEG) with a reasonable spatial resolution (Hansen et al., 2010).

In line with the advent of producing SL experiences in the lab, the participants employed in the present study are long-term mindfulness meditation practitioners. Mindfulness is defined and practiced as a non-judgmental awareness of bodily or mental experiences arising in the present moment. Regardless of how pleasant or unpleasant the arising experiences are, the meditator trains not to cling to, nor to push them away, but rather to treat them with acceptance, openness and curiosity, watching them arise, play in the theater of the mind and finally dissolve back into the space of the mind (Kabat-Zinn, 1990). Mindfulness is a current and widespread form of Buddhist practice (Williams and Kabat-Zinn, 2011), and has been shown to enhance cognitive functions such as attentional abilities, emotional regulation, executive functions and memory (Chiesa and Serretti, 2010; Chiesa et al., 2011), altering the brain circuits and neuropsychological mechanisms underlying these functions (Cahn and Polich, 2006; Davidson and Lutz, 2008; Lutz et al., 2008; Hölzel et al., 2011b), and even altering brain structure in regions typically activated during mindfulness meditation (Lazar et al., 2005; Hölzel et al., 2008, 2011a).

One of mindfulness's mechanisms of action is an altered sense of self (Hölzel et al., 2011b). Mindful awareness induces a sharper sense of the normally perceived subjective sense of self (Lutz et al., 2008), but treats it as an object of meditation. This cultivated shift to an "observer perspective" (Kerr et al., 2011) induces a change in the perspective of self and first-person experience. Indeed, a recent integrative theoretical framework and systemsbased neurobiological model suggests understanding mindfulness by focusing on self-processing and the neural networks underlying self-awareness, self-regulation, and self-transcendence (Vago and Silbersweig, 2012). A growing number of studies show that mindfulness alters DMN and self-related activity and connectivity (EEG: Berkovich-Ohana et al., 2012; Lehmann et al., 2012; 
fMRI: Pagnoni et al., 2008; Brewer et al., 2011; Ives-Deliperi et al., 2011; Froeliger et al., 2012; Hasenkamp and Barsalou, 2012; Taylor et al., 2013). In particular, Farb et al. (2007) used fMRI and a mindfulness-based stress reduction (MBSR, Kabat-Zinn, 1982; Kabat-Zinn et al., 1992) intervention to dissociate narrative from experiential modes of processing. The present study continues Farb et al. (2007) in using mindfulness meditators for revealing the neural correlates of momentary (parallel to MS) and across-time (parallel to NS) self processing, but goes further in exploring SL: momentary phenomenal experience free of the sense of agency and ownership. Figure 1 illustrates the encapsulated relationship between NS, MS and SL.

The working basis for the present study's design is that longterm mindfulness meditators: (1) are adept in keeping their attention for extended time periods on an object of choice, be it a physical object, the breath, or a produced state of self; and (2) develop through practice their goal of dissolving the experience of a fixed subjective core comprising their self-identity. Thus, such participants were recruited and requested to mentally project states representing NS, MS, and SL, while their brain activity was recorded by MEG. The purpose of the study is to map the differential neural activity related to NS and MS, as well as characterize SL, a present-centered conscious experience devoid of an experiencing subjective self. The study's aims and hypotheses are to:

1. Map the neural correlates of NS. Given that MS is at play also during NS, contrasting the two conditions is expected to reflect NS attenuation, and is hypothesized to result in a reduction of mPFC high-gamma oscillatory activity. This part of the study is expected to bridge results from the prevalent fMRI imaging literature and the present MEG methodology.

2. Map the neural correlates of MS. Given that both MS and SL share a present-centered experiential aspect, differing only

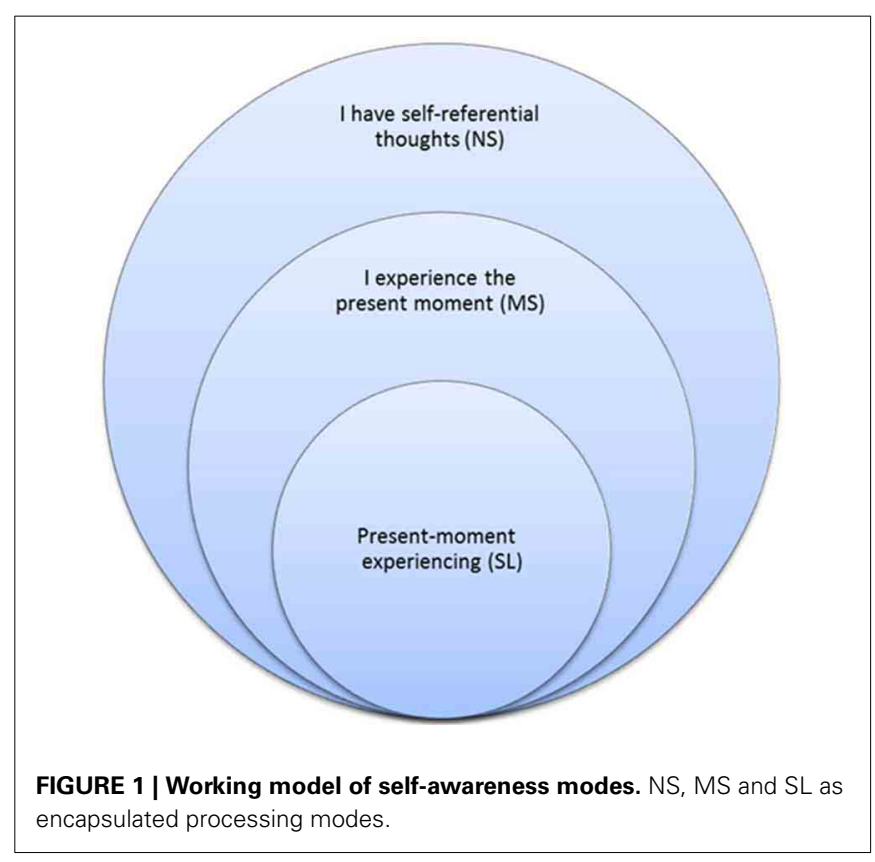

in terms of the experiencer-the agency/ownership aspects accompanying experience, contrasting MS and SL is expected to reflect the neural correlates of MS attenuation. Here predictions are less clear, nevertheless, the IPL and insula are likely to play roles. Localizing this differential activation within the frequency domain will be a novel contribution of the present study.

3. Use first-person reports for grouping the $M E G$ data and identifying the neural correlates of the subjective aspects of the Buddhist-described "selfless" experience.

\section{MATERIALS AND METHODS \\ PARTICIPANTS}

Sixteen experienced meditation practitioners were recruited for the research project. Two participants' data were discarded early on in the experiment. The first due to complaints of tiredness and lack of focus, and the second due to back pain (to the point of stopping the MEG recording). In addition, in order to establish a common frame of reference for the first-person descriptions, as well as control for confounds that might result from different sources of training, only participants practicing very similar forms of meditation were included in the study. Thus, the data of two further participants (Zen and non-dual practitioners, see Lutz et al., 2007 for details on these forms of meditation) were not analyzed. The remaining 12 practitioners, all mindfulness meditators practicing similar forms of Vipassana, either originating from or inspired by the Buddhist Theravada tradition, comprise the participants of the present study. All are right-handed (9 males and 3 females, mean age 45.2, $S D=11.3$, ranging from 31 to 66) with no history of mental or neurological disease. All of the participants are long-term practitioners with an average of $16.5(S D=7.9$, ranging from 9 to 34$)$ years of meditation practice, and an average of 11,225 ( $S D=9909$, ranging from 1290 to 29,293 ) total hours of meditation practice. All the performed procedures are in compliance with the Code of Ethics of the World Medical Association (Declaration of Helsinki), and were approved by the Research Ethics Board of Bar-Ilan University. The participants gave their written consent and were financially compensated for their time.

\section{PRE-RECORDING PROCEDURES}

The participants were welcomed and introduced to the experiment and the research facility. They then filled out forms noting their agreement to participate in the experiment, their personal details, and a form estimating their formal meditation experience. Pre-task procedures included an average of $45 \mathrm{~min}$ of clarifying the study's setup, tasks and stimuli using a PowerPoint presentation and allowing time for questions and discussion. In this way, misunderstanding, alteration, or rejection of the scripts provided by the researchers, were minimized (Roepstorff, 2001).

\section{TASKS}

The experiment included seven experimental sessions. Of these, only the "self" session (fifth in order) is reported here. Each session consisted of performing tasks during which the participant's brain activity was recorded. This was followed by an interview conducted via the intercom system, during which brain activity 
was not recorded. The participants were encouraged to stretch their limbs and relax during the interview, but were requested not to move and to keep their eyes closed while performing the tasks. To correct for head and body movements during the interview session, head-shapes were re-registered at the beginning of each session. A 20-min break was suggested to the participants after completing the 5th session of the experiment, during which refreshments were offered. Total time in the MEG ranged from 2 to $3 \mathrm{~h}$. The participants' condition was closely monitored throughout the experiment via the intercom (during the interview sessions) and the closed-circuit TV camera (at all times). In addition, participants were asked a number of times throughout the experiment if they were tired and needed an additional break.

The task relevant to the present study is the "self task." Participants were requested to mentally project themselves into certain self-related states, which had been described and discussed during the PowerPoint presentation. The session included 3 conditions, each repeated 3 times in succession for $30 \mathrm{~s}$. This more ecologically-valid design (in contrast to the commonly employed event-related designs) was chosen due to mediators' heightened capacities in directing and sustaining attention (BrefczynskiLewis et al., 2007; Lutz et al., 2008). The first 4 s of each 30-s epoch were omitted so as to allow participants sufficient time to enter the states (SL in particular). This decision was made after consulting a well-known, very-long-term, meditation teacher, concerning the study design, and after 2 pilot runs (with two of the authors, Aviva Berkovich-Ohana and Yair Dor-Ziderman, who are also long-term meditators). A recording with instructions for each condition was sounded, after which the participant performed the requested task. At the end of the $30 \mathrm{~s}$, a sound was heard indicating to the participant to stop and rate task performance success (on a 1-3 scale). This measure was incorporated in order to allow post-hoc identification of bad trials (button press of 1). However, as none of the participants in any of the conditions reported here indicated such bad trials, this measure was not further used. After pressing the corresponding button, the next instruction was delivered. The session was followed by a structured interview conducted via the intercom system.

The exact instructions for each self-projected condition were:

i "narrative" condition (NS)_ "Try to think what characterizes you."

ii "minimal" condition (MS) - "Try to experience what is happening to you at the present moment."

iii "selfless" condition (SL)_ "Try to experience what is happening at the present moment, when you are not in the center."

\section{DATA ACQUISITION}

\section{MEG}

MEG recordings were conducted with a whole-head, 248-channel magnetometer array (4-D Neuroimaging, Magnes $3600 \mathrm{WH}$ ) in a magnetically-shielded room. Reference coils located approximately $30 \mathrm{~cm}$ above the head oriented by the $x, y$, and $z$ axes were used to remove environmental noise. Head position was indicated by attaching 5 coils to the scalp and determining, to a $1 \mathrm{~mm}$ resolution, their position relative to the sensor array before and after measurement. Head localization was performed before and after each set of tasks to determine degree of head movement. Head shape and coil position were digitized using a Pollhemus FASTTRAK digitizer. Brain signals were recorded with a sample rate of $1017.25 \mathrm{~Hz}$ and an analog online $0.1-400 \mathrm{~Hz}$ band-pass filter. The instructions for each condition were presented using E-prime 1.0 and delivered via a STAX SRS-005 amplifier and SR-003 push-pull electrostatic ear speakers coupled by a vinyl tube to silicon earpieces to prevent magnetic noise within the shielded room. Task performance ratings were collected using a LUMItouch photon control response box.

\section{Subjective reports}

Retrospective reports. Participants were asked to provide retrospective reports regarding their perceived (relative to past experiences) success and stability (on a 1-10 scale, with 1 denoting "very low" and 10 denoting "very high") in performing the tasks, as well as report on the emotional content of their experiences during the different tasks.

Introspective reports. Participants were asked to describe their SL experience freely and in their own words, without reflection or judgment (Jack and Roepstorff, 2002; Schooler, 2002; Lutz and Thompson, 2003). In addition, the descriptions were collected immediately after they were produced in order to minimize reliance on episodic recall (Jack and Roepstorff, 2002).

\section{MEG DATA ANALYSIS \\ Cleaning and preprocessing}

Data processing and analysis was performed using Matlab ${ }^{\circledR}$ R2009b and FieldTrip toolbox for MEG analysis (Open Source Software for Advanced Analysis of MEG, Oostenveld et al., 2011). Data were cleaned for line frequency (by recording on an additional channel the $50 \mathrm{~Hz}$ from the power outlet, and subtracting the average power-line response from every MEG sensor), and $24 \mathrm{~Hz}$ building vibration (measured in $x, y$, and $z$ directions using 3 Bruel and Kjaer accelerometers) artifacts (Tal and Abeles, 2013). The data from the 3 "self" tasks were then segmented into nonoverlapping 2-s epochs. Each epoch was visually examined for muscle and jump (in the MEG sensors) artifacts. Contaminated epochs were discarded. No malfunctioning MEG sensors were identified. To ensure the removal of all heartbeat, eye, and muscle artifact, an independent component analysis (ICA) was performed on the data (Jung et al., 2000). Segmented data were down-sampled to $339(1017 / 3) \mathrm{Hz}$ to speed up data decomposition. The data were then decomposed into a set of independent components (248, as the number of sensors) ordered by degree of their explained variance. Components indicating heartbeats or eye movements were determined from a visual inspection of the $2 \mathrm{D}$ scalp maps and time course of each component. $2.6 \pm$ 1.2 components were taken out on average, and the remaining components were then used to reconstruct the pre down-sampled data.

\section{Sensor-level analyses}

In order to level the number of trials for all participants and conditions, the first 32 of the remaining epochs were marked as the data for further sensor-level analyses. The segmented 2-s 
epochs were multiplied by a Hanning taper, and subjected to a Fast Fourier Transformation (FFT) for the frequencies ranging from 0.5 to $100 \mathrm{~Hz}$. This resulted in a power spectrum with a frequency resolution of $0.5 \mathrm{~Hz}$ for each epoch. The power spectra were then averaged across the epochs of each condition, thus obtaining the mean power for each condition and participant. The next step involved calculating, for each frequency of each sensor of each participant, a power percent-in-signal-change (PSC) metric, for estimating power differences in NS vs. MS and MS vs. SL. PSC was computed in the following manner: for sensor $S$, frequency $f$, and power values of conditions $A$ and $B$, PSC $[S(f)]=$ $[(A / B)-1]$ if $A>=B$, and [1- $(B / A)]$ if $B>A$. This manipulation yields a balanced PSC distribution centered on 0 . Each participant's PSC values for the two comparisons were then collapsed across all sensors, and averaged across the delta $(0.5-3.5 \mathrm{~Hz})$, theta $(4-7.5 \mathrm{~Hz})$, alpha $(8-12.5 \mathrm{~Hz})$, beta $(13-25 \mathrm{~Hz})$, gamma $(25.5-59.5 \mathrm{~Hz})$, high-gamma $(60-80 \mathrm{~Hz})$, and very-high-gamma $(80.5-100 \mathrm{~Hz})$ frequency bands. To reduce dimensionality prior to localization, 1 -sample $t$-tests were performed for each frequency band and for each comparison against the null hypothesis that the PSC measures came from a continuous, normal distribution with a zero mean. Results were then Bonferroni-corrected. Finally, 2D scalp topographies of the mean PSC in the significant frequency bands and comparisons were created.

\section{Source-space projection}

Localization was performed for the frequency bands which evidenced significant PSC in the sensor-level data. Sources were estimated using Synthetic Aperture Magnetometry (SAM, Robinson and Vrba, 1999). SAM is an adaptive nonlinear minimumvariance beamformer algorithm. It calculates the signal covariance from the MEG sensor data and uses it in conjunction with a forward solution for the dipoles at each 3D brain voxel (of a specified size) to construct optimum spatial filters. The spatial filtering suppresses interference of unwanted signals from other locations.

For source estimation, the pre-ICA data were used. A number of works have shown that interfering biomagnetic sources such as cardiac, respiratory, and eye movements are effectively suppressed by beamforming (e.g., Sekihara et al., 2006; Brookes et al., 2008, 2011). Data were band filtered (using the SAM default IIR filter) for each participant and condition in the frequency bands specified through the sensor-level analysis. Covariance matrices, and subsequently SAM weights, were computed for each 5 cubic$\mathrm{mm}$ voxel using the data from the two conditions participating in each signal change calculation, for each frequency-band-filtered time-series data. For each voxel, the data were multiplied by the weights, thus creating "virtual sensor" time-series, which were then transformed via FFT to the frequency domain, thus deriving power values. Finally, PSC values (same metric as the one described in the sensor-level analysis section, pseudo-F in SAM) were computed for each comparison, participant and each and every voxel.

To facilitate group analysis, head models were constructed by co-registering each participant's SAM volume to a previously obtained MRI scan (T1-weighted anatomical images acquired with high-resolution 1-mm slice thickness, obtained by one of the authors (Aviva Berkovich-Ohana) by means of a 3T Trio
Magnetom Siemens scanner located at the Weizmann Institute of Science, Rehovot, Israel) based on the position of the fiduciary markers established during the digitization phase. Each participant's MRI image and its co-registered SAM volume were then transposed into a common anatomical space (Talairach coordinates, Talairach and Tournoux, 1988). Voxel-level group statistics, for each comparison and frequency band, were conducted using a non-parametric permutation analysis procedure (2000 permutations, Nichols and Holmes, 2001; Singh et al., 2003), and corrected for multiple comparisons based on a Monte Carlo simulation of random noise distribution (using AFNI's 3dClustSim module, Forman et al., 1995).

\section{NEUROPHENOMENOLOGICAL ANALYSIS Subjective reports}

Success and stability. For assessing whether participants' ratings for perceived success and stability were different for the different tasks, repeated-measures ANOVA was conducted for success and stability as dependent variables.

Emotional content. Participant reports of emotional content during each task were collected and arranged in 4 categories: neutral-here participants either reported no emotional content or explicitly stated a neutral state; positive-here participants reported only positive emotions (such as enjoyment, comfort, quiet, pleasant, rest, and lightness); negative-here participants reported only negative emotions (such as pride, fear, anxiety, confusion, insecurity, and dislike), and mixed-which included reports of both positive and negative emotions. In addition, a number of participants spontaneously reported low level of emotions (NS-4 participants, 2 in the negative category and 2 in the mixed category; SL-1 participant in the mixed category). A note regarding the categorization of "pride" as a negative emotion: this is in alignment with the Buddhist context (Goleman, 1995; Chambers et al., 2009), given that the participants are long-term practitioners of Buddhist traditions.

Meditation experience. Meditation experience was gauged using a normalized measure incorporating both total number of years and hours of meditation. The maximum values of meditation year and hour estimates were extracted, and all other values were divided by them, resulting in values between 0 and 1 . The two metrics were then averaged, giving equal weight to meditation years and hours.

First-person SL descriptions. A careful reading by the authors of the participants' first-person descriptions of their SL experiences indicated three rather broad but distinct types of experiences. Age was ruled out as a confounding factor [ANOVA, $F_{(1,11)}=$ $3.76, n s]$. The suggested categorization was further validated by presenting the raw participant descriptions and category explanations (as presented below but without the examples) to 12 naïve referees (graduate students and postdoctoral researchers), and asking them to categorize the descriptions according to the suggested scheme. Descriptions which were categorized differently than the suggested scheme by more than one referee were excluded from the analysis. Two descriptions were thus removed 
(sub14 and sub16's, 4 referees categorized each of them differently), resulting in 10 SL descriptions. The participants' descriptions (including those finally excluded from the analysis) and their categorization are presented below in Table 1. The suggested categories are:

a. Lack-of-ownership (LO): The 4 participants in this category reported experiencing what was happening, only with the sense of agency/ownership absent. As an example, participant sub12 described: "It was emptiness, as if the self fell out of the picture. There was an experience but it had no address, it was not attached to a center or subject..."

b. Altered-experience (AE): The 4 participants in this category reported an altered experience of their bodies/senses/spatialcontext. For example, sub11 reported: "On the level of feeling and sensing - as if I took a step back and am looking at myself from the back. I see myself but am also aware of what is happening around..."

c. Less-happening ( $\mathrm{LH})$ : The grouping of this category was somewhat looser than the other categories. The 4 participants in this category reported a quieting or general relaxation of body, reflectivity, cognition, or experience in general. For example, participant sub6 reported: "Very pleasant and relaxed and quiet. It was the most devoid of effort relative to the previous one..."

\section{MEG source estimates}

To identify within the MS vs. SL beta-band (the only frequency band relevant for characterizing SL-see results section) network regions specifically correlated with the phenomenological categories, MEG source estimates of each phenomenological category (vs. the other two categories) were derived in a manner similar to the one described above. Group statistics, limited to the network of interest (significant MS vs. SL beta band regions), were computed on the Talairach-transformed individual images using non-parametric random permutations with a 2 -sample $t$-test statistic.

\section{RESULTS}

\section{SUBJECTIVE REPORTS}

The first-person reports indicated that the participants were able to successfully produce the different self-states. The means for task success were high (on a 1-10 scale with 1 denoting "very low" and 10 denoting "very high") for the NS, MS, and SL tasks (8.6 \pm 0.9 , $7.8 \pm 1.4$, and $8 \pm 1.2$, respectively). In addition, participants reported high measures of task stability: $8.2 \pm 1.6,8 \pm 1.4$, and $7.6 \pm 1.5$ for NS, MS, and SL, respectively. These indicate that the participants managed-in their subjective experience-to produce and maintain the requested self-states in a stable manner for the task duration. The ANOVA indicated no significant differences between the states for both task success $\left[F_{(2,11)}=2.2\right.$,

Table 1 | SL descriptions and their phenomenological categorization.

\section{Phenomenal categories during SL}

\section{Lack-of-ownership (LO)}

Sub4: "The question was 'what was happening?' As a sort of subjectivity focus, which was softened and dissolved. And all that was left was what was happening not to me."

Altered-experience (AE)

Sub5: "Like in a dream. Like I'm not awake now but dreaming. Sensations of all kinds of things flickering... A sort of meditative phenomena and flickering of light and darkness-difficult to describe in words. Like colored dots on black. Wide and open, something was liberated."

Sub8: "Floating above the entrance door, between the room and the lab..."

\section{Less-happening (LH)}

Sub1: ". . felt that less was happening, or that not much was happening."

Sub9: ". . I I understood that it was just a sensation, it was not the hand itself, and the sensation was liberated, and so on in other areas. There were jumps of liberation; there was a deep thought that all this was not mine."

Sub12: "It was emptiness, as if the self fell out of the picture. There was an experience but it had no address, it was not attached to a center or subject. It was not $100 \%$, but there was no sense of an object there running the show. Emptiness is the best word."

Sub14: "It was to be aware of the body, the sensations, pulse, location of limbs, sounds and sights—to be only a witness to all this."

\section{EXCLUDED FROM THE ANALYSIS}

Sub16: "I rested within the body, and from the perspective of how I perceive myself as NA I kind of lost that. It was like being within a space that is a space in distinction to

something with sides and a center."
Sub11: " . . as if I took a step back and am looking at myself from the back. I see myself but am also aware of what is happening around..."
Sub2: “. . . less judgmental element; less naming of the experience, less verbally. Technique was something like 'what is happening to you right now' task, but more relaxed."

Sub6: "Very pleasant and relaxed and quiet. It was the most devoid of effort relative to the previous ones. Resting within the experience and presence, easy and pleasant..."

\section{EXCLUDED FROM THE ANALYSIS}

Sub14: "... There was a feeling of a shift in alertness, a cessation of reflectivity. A different kind of quiet. The language changed."

Participants' first-person SL experiences descriptions arranged by the suggested categorization scheme. Left column = LO category; middle column = AE category; right column $=$ LH category. Descriptions excluded from the analysis due to the validation process are so noted. 
MSE $=1.58, n s]$ and task stability $\left[F_{(2,11)}=1.08\right.$, MSE $=1.39$, $n s]$. These results help rule out attribution of between-conditions differences to task difficulty.

The emotional content reported by the participants did differ between conditions. The emotional profiles during each of the tasks are depicted in Figure 2. A marked difference can be observed between the NS and the other two self-tasks. While in the NS condition 10 participants reported negative (5) or mixed (5) emotions, in the MS and SL conditions only one participant reported negative or mixed emotions, and on the other hand, 8 (SL) and 9 (MS) reported a neutral affective state, while the remaining 3 and 2 (respectively) participants reported positive emotions.

\section{SENSOR-LEVEL RESULTS}

Of the frequency bands tested (delta, theta, alpha, beta, gamma, high-gamma, very-high-gamma), the sensor level results indicated a significant decrease in global (all 248 sensors) PSC between the NS and MS conditions only in the high gamma $60-80 \mathrm{~Hz}$ band (mean PSC $=-0.052 \pm 0.0472 ; p<$ 0.02 , 1-sample $t$-test, Bonferroni-corrected). In contrast, the only frequency band evidencing a significant PSC when contrasting the MS and SL conditions was the $13-25 \mathrm{~Hz}$ beta band (mean PSC $=-0.103 \pm 0.1107 ; p<0.05,1$-sample $t$-test, Bonferronicorrected). The other frequency bands evidenced no significant power PSC differences-even prior to the Bonferroni correction. Figure 3 provides 2D topographic representations of the sensor level power PSC in these two significant frequency bands. Note the different topography for the two comparisons, with the highgamma NS vs. MS decreases in power occurring predominantly over frontal-left electrodes and the beta MS vs. SL decreases being more central and right lateralized.

\section{SOURCE LOCALIZATION ESTIMATES}

SAM beamforming source estimates are reported for the $60-80 \mathrm{~Hz}$ high-gamma band for NS vs. MS, and in the $13-25 \mathrm{~Hz}$

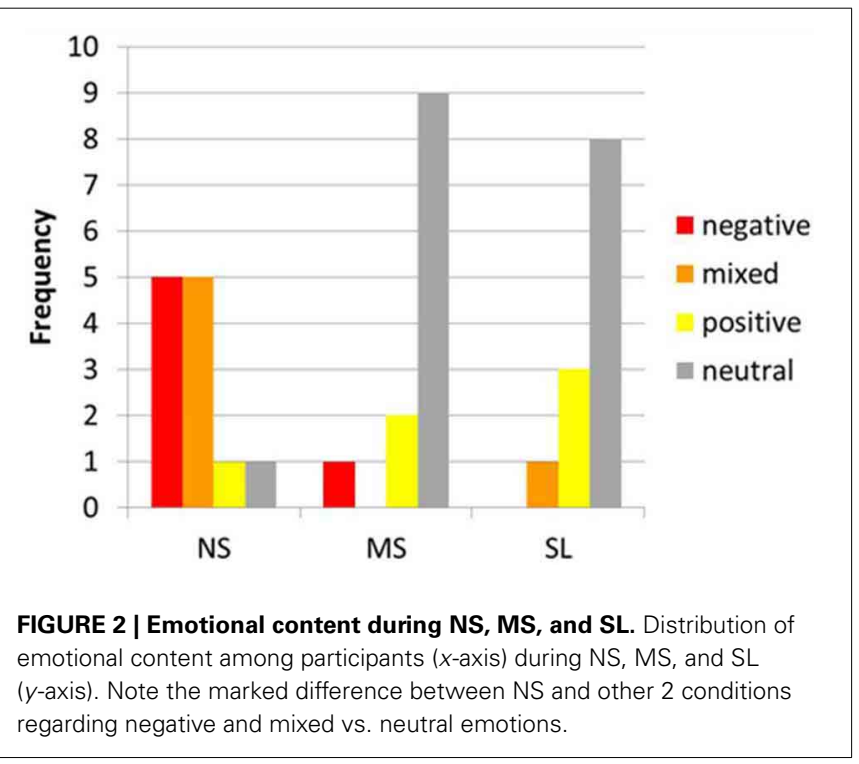

beta band for MS vs. SL-as indicated by the sensor-level data. As a comparative measure, the complementing high-gamma (for MS vs. SL) and beta (for NS vs. MS) localization solutions are also reported.

\section{NS vs. MS source estimates}

Resulting NS vs. MS $60-80 \mathrm{~Hz}$ high-gamma band images were thresholded at the maximum $t$-value possible for a nonparametric random permutation analysis with 2000 permutations ( $t=4.863$, see methods section for details), yielding 2 robust $(p<0.0005$, corrected) rather large clusters (314 and 264 voxels) spanning almost exclusively frontal regions, and all indicating decreases in gamma power in MS relative to NS (reflecting NS attenuation, see introduction). The larger cluster (mean PSC -0.083, A1 and A2 in Figure 4) was more posterior, including right and left precentral gyrus, middle cingulate cortex, middle frontal gyrus and thalamic regions. In the right hemisphere, the cluster included the posterior part of the inferior frontal gyrus and operculum, lentiform nucleus and caudate body. Two thirds of the cluster was in the right hemisphere; however, the left hemisphere PSC was stronger. The second cluster (264 voxels, mean PSC - 0.086, B1 and B2 in Figure 4), was more anterior (prefrontal) and mostly left-lateralized (76\%). The cluster spanned bilateral dorsal and anterior regions of the medial frontal gyrus, superior frontal gyrus, and dorsal ACC. More ventrally, left-lateralized regions included subgenual ACC, mid orbital gyrus, middle frontal gyrus and middle cingulate cortex. See Figure 4 and Table 2 for more details and a visual depiction.

In the beta band $(13-25 \mathrm{~Hz})$, the NS vs. MS contrast also resulted in significant PSC results, albeit markedly less robust compared to the gamma band results and solely in posterior regions. These images were thresholded at $t=3.887$, yielding 3 significant clusters at the $p<0.0025$ (corrected) level. Righthemisphere regions included mainly the fusiform and middle temporal gyrus (48 voxels, mean PSC $-0.148, \mathrm{C1}$ in Figure 4), and a small cluster in the right cerebellum ( 8 voxels, mean PSC -0.141, not shown). Left-hemisphere regions encompassed mainly the middle occipital and lingual gyrus (36 voxels, mean PSC -0.099, C2 in Figure 4). See Figure 4 and Table 2 for more detail and visual depiction.

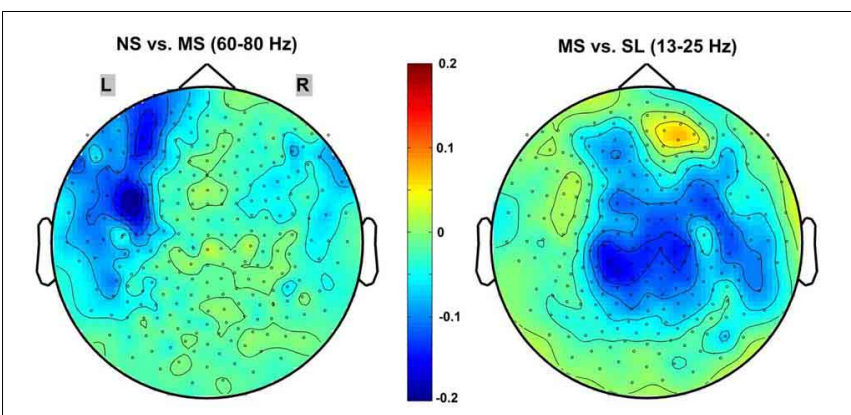

FIGURE 3 | 2D scalp maps of frequency bands with significant power PSC. 2D topographic representations of significant sensor-level power PSC for the NS vs. MS high-gamma $60-80 \mathrm{~Hz}$ (left), and MS vs. SL beta $13-25 \mathrm{~Hz}$ (right). Dots on the map represent sensors; color bar scale indicates PSC from 0.2 (dark red) to -0.2 (dark blue). 


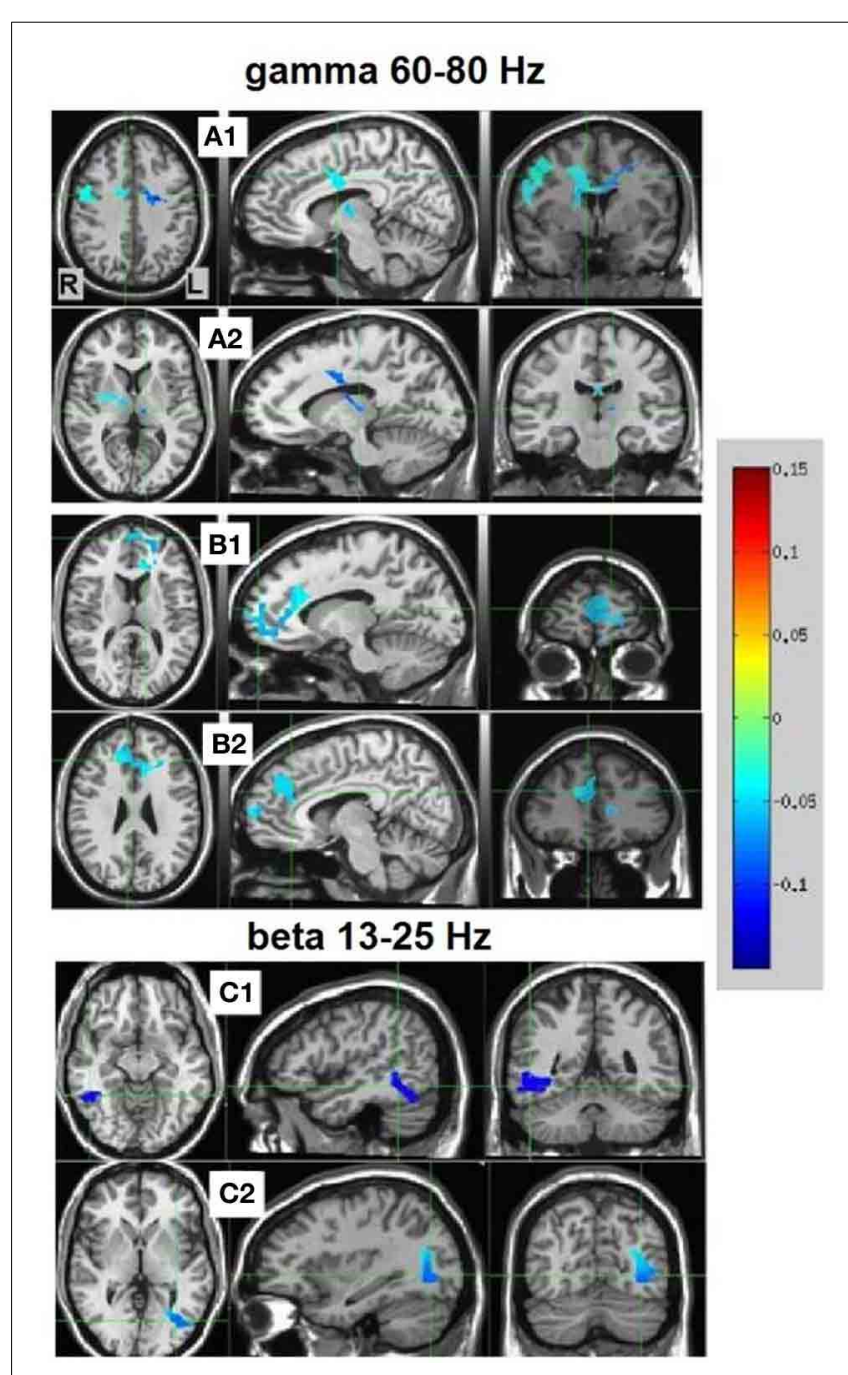

FIGURE 4 | NS vs. MS beamforming source estimates in the gamma $(60-80 \mathrm{~Hz})$ and beta $(13-25 \mathrm{~Hz})$ frequency bands. Axial, sagittal, and coronal views (left to right) of group ( $n=12$ ) PSC source estimates overlayed on the Colin template. Note that in all images right and left sides are crossed. Color bar indicates PSC degree. Gamma band clusters: Cluster $A$ is presented in 2 views. Crosshairs in (A1) are on the right medial anterior cingulate, and in (A2) on the left thalamus. Cluster B is presented in 2 views. Crosshairs in (B1) are on the left anterior cingulate, and in (B2) on the right anterior medial prefrontal cortex. Beta band clusters: Crosshairs in (C1) are on the right fusiform gyrus, and in (C2) on the left middle occipital gyrus.

\section{MS vs. SL source estimates}

Resulting MS vs. SL $13-25 \mathrm{~Hz}$ beta band source estimates were thresholded at $t=3.887$, yielding six clusters (for a total of 390 voxels) significant at $p<0.0025$ (corrected), all indicating decreased beta power in SL relative to MS (reflecting MS attenuation, see introduction). No significant clusters were found in the high-gamma band range. The largest cluster (182 voxels, mean PSC - 0.067, A1 and A2 in Figure 5) consisted of prefrontal and left lateralized regions including the superior frontal gyrus, ventral $\mathrm{MPFC}$, and rostral ACC; bilateral regions including the subgenual ACC, mid orbital, and rectal gyrus; and a region located in the right middle frontal gyrus. The 2 nd cluster (109 voxels, mean PSC -0.08 , B in Figure 5) was completely in the right hemisphere and included regions from the postcentral gyrus, middle cingulate cortex, paracentral lobule, precuneus, and posterior cingulate cortex (PCC), and the IPL. The 3 rd cluster (66 voxels, mean PSC -0.072, C in Figure 5) included large portions of the left thalamus and lentiform nucleus, extending medially to the left posterior insula. The 4 th cluster (13 voxels, -0.1 PSC, D in Figure 5) was more anterior and lateral compared to the 2 nd cluster, and included regions of the right IPL and postcentral gyrus. The 5th cluster (11 voxels, -0.081 PSC, D in Figure 5) was located in the left IPL, and the 6th cluster ( 9 voxels, -0.105 PSC, not shown) in the right precentral gyrus and the posterior middle frontal gyrus. See Figure 5 and Table 3 for more details and a visual depiction.

\section{NEUROPHENOMENOLOGY}

The neurophenomenological data consisted of the participants' first-person descriptions of their SL experiences, and the MS vs. SL beta-band network described above. The phenomenal categorization yielded three categories ( $\mathrm{LO}, \mathrm{AE}$, and $\mathrm{LH}$, as detailed in the methods section). The LO category participants were also the most experienced and formed a distinct group with meditation experience being qualitatively higher than the members of the other categories (see Figure 6). The other two experience categories were mixed in terms of their members' meditative experience.

Source estimates characterizing each phenomenal category were obtained by pitting the beta-band MS vs. SL images of the participants in each phenomenological category against the other two categories. Two significant cluster were found, distinguishing LO participants $(n=4)$ from the others $(n=6$, not including "unclear" category). The first cluster was located in the right IPL and the second in the left dorsomedial thalamus. The other phenomenological categories did not yield any significant clusters. In addition, the same analysis but within the gamma-band NS vs. MS images yielded no significant source estimates for any of the phenomenal categories. Thus, methodological triangulation (Gallagher, 2002; Jack and Roepstorff, 2002) of distinct phenomenology, meditative expertise and SAM source estimates in the beta band, culminated in a distinct neurophenomenological characterization of the LO category. Visual depictions of these regions, along with cluster details are presented in Figure 7.

\section{ISSUES OF VALIDITY Myogenic artifact}

As participants reported a more neutral emotional state during MS relative to NS, it might be argued that the reported decrease in high-gamma power (in which myogenic artifacts may manifest) reflects a more relaxed state and thus reduced muscle-activity, and not a difference in neural activity. There are, however, a number of arguments that make this unlikely: (1) Muscle artifacts are less of a problem in MEG relative to EEG measurements, partly due to the possibility of reliably localizing the effects' activation locus. In fact, MEG has been previously employed for determining whether EEG high frequency 
Table 2 | NS vs. MS beamforming solutions for gamma $(60-80 \mathrm{~Hz})$ and beta $(13-25 \mathrm{~Hz})$.

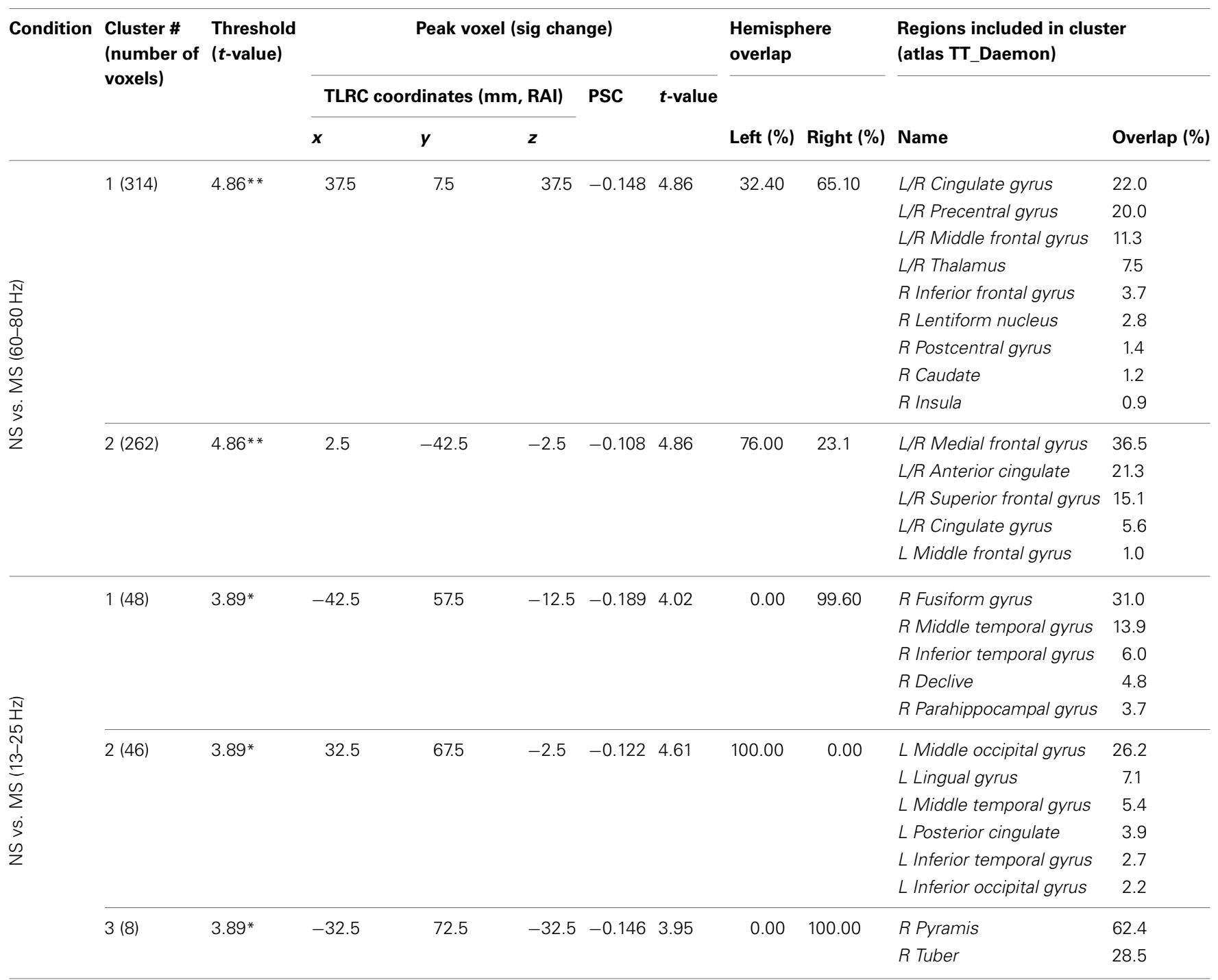

Information supplied includes number of voxels in each cluster, thresholds, peak voxel characteristics, hemispheric overlap, and brain regions included in the cluster. The Afni supplied TT Daemon atlas was used. Due to poor resolution and signal leakage to non-brain regions, overlap percentages do not always add up to $100 \%$. ${ }^{*} p<0.0025 ;{ }^{* *} p<0.0005$ (corrected).

components may have a muscular origin (Zimmermann and Scharein, 2004; Claus et al., 2012). (2) Pre-emptive measures were taken to counter muscle artifacts during both data collection (supine positioning, eyes closed) and data cleaning (visual inspection of all the data). (3) The high-gamma effect found here is dissimilar to typical myogenic artifacts (described in Muthukumaraswamy, 2013) in several ways. The effect, on the sensor level is: (a) highly lateralized (and it is unlikely that for all the participants the artifact was confined to one hemisphere); (b) does not extend to the montage borders (which is the normal case for muscle artifacts); and (c) the activity is narrowly confined to the $60-80 \mathrm{~Hz}$ band (while myogenic artifacts tend to be "patchy" and to command a wider spectrum). (4) Finally, the reported regions are consistent with a well-established body of literature.
In addition, in order to empirically test the link between increased emotionality, the myogenic artifact and increased high-gamma PSC, a further analysis was conducted. The values of the peak activation voxels of each of the two NS vs. MS clusters (reported in Table 2), were extracted for each participant (by transposing the group Talairach coordinates back to each participant's MRI image and its co-registered SAM volume). Then, these values (for each voxel) were sorted into two groups: participants who spontaneously reported little or no emotions (4 and 1 participants, respectively) during NS, and participants who did not (7 participants). There were no significant differences between the groups for both tested voxels (2-sample $t$-test, $n s$ ), with the PSC means of the decreased emotionality group being actually higher than the normal group (contrary to what could be expected if the tested hypothesis was correct). 


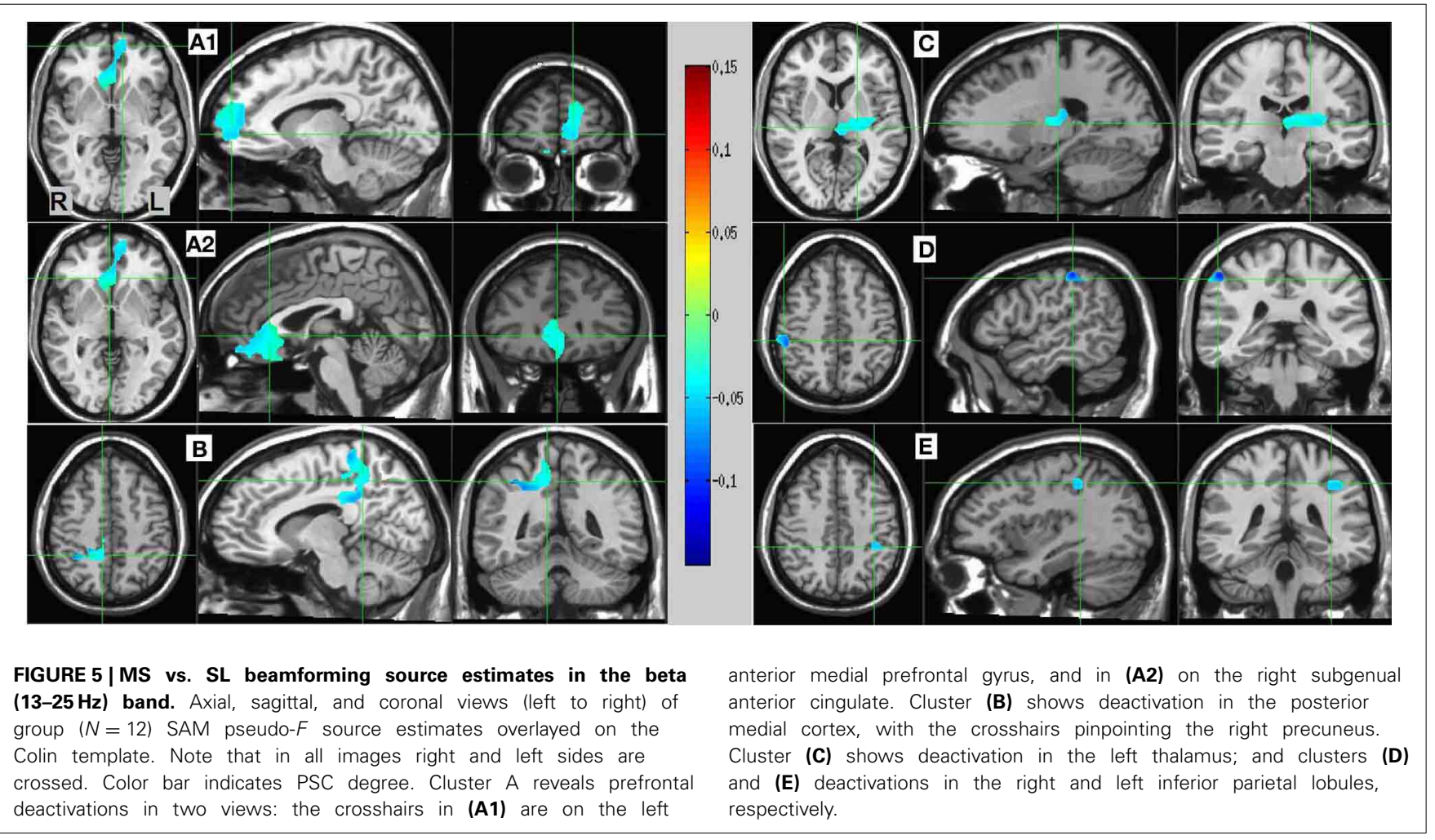

\section{Attentional demands}

To rule out confounds resulting from attentional demands being different for the different tasks, we ran some additional analyses (on top of the subjective ratings of task success which evidenced no significant differences). The bulk of the meditation-related literature (see Cahn and Polich, 2006 for an extensive review) reports changes in anterior and posterior alpha and/or mid-line theta oscillatory activity as measures gauging the concentrative attention-related aspects of meditation. Thus, we checked (using a robust, cluster-based non-parametric permutations approach, Maris and Oostenveld, 2007) whether any significant clusters in these frequency bands could be identified. None where found. In addition, activity in the dorsolateral PFC has been specifically found to reflect task difficulty, in particular regarding longterm meditators (Brefczynski-Lewis et al., 2007). The fact that the present results showed no sign of dorsolateral PFC activity changes between the conditions can be taken as yet another indication that attentional demands do not account for the reported results.

\section{DISCUSSION}

In summarizing the findings of the present study, three main points emerge: (1) NS attenuation is characterized by decreases in high-gamma $(60-80 \mathrm{~Hz})$ oscillatory activity. These are lefthemisphere-dominated and manifest in frontal, thalamic and extensive dorsal and ventral mPFC regions, in line with the related fMRI literature; (2) MS attenuation is characterized by decreases in beta-band $(13-25 \mathrm{~Hz})$ oscillatory activity in both overlapping (with the gamma network) regions including the left ventral mPFC and thalamus, and a right pre-motor region, and non-overlapping regions including the right PCC and precuneus medially, and bilateral but right-hemisphere dominated IPL. While these regions have been previously tied to MS processing, the frequency band hosting these deactivations - the beta band-is a novel finding of the present study; (3) Phenomenal characterization of participants' descriptions of their SL experiences yielded three distinct categories of experience. In particular, the LO group, whose experiences indicated a sharp attenuation of the sense of agency/ownership, and who were also distinct in terms of their greater meditative expertise, also evidenced a distinct neural signature characterized by a further attenuation of the right IPL and left dorsomedial thalamus in the beta band. The implications of these results are discussed in the following paragraphs.

\section{NS ATTENUATION IS LINKED TO DECREASED mPFC CORTICAL ACTIVITY AND DECREASED NEGATIVE EMOTIONS}

As predicted, frontal, and especially medial prefrontal, highgamma-band decreases in oscillatory activity resulted from attenuating the narrative mode of processing toward a minimal experiential mode (NS vs. MS, Figure 4). The link between NS attenuation and reduced mPFC activity, is, as noted, supported by virtually all fMRI research and review studies regarding self-referential processing (Gusnard et al., 2001; D’Argembeau et al., 2005; Northoff et al., 2006; Christoff et al., 2011; Qin and Northoff, 2011; Whitfield-Gabrieli et al., 2011; Kim, 2012). Also, as mentioned, intracranial EEG studies (Nir et al., 2007; Jerbi et al., 2010; Ossandón et al., 2011; Ramot et al., 2012) correlate self-referential and DMN blood-oxygenation-level-dependent (BOLD) reductions to suppressed high gamma-band oscillatory 
Table 3 | MS vs. SL beamforming solutions for gamma $(60-80 \mathrm{~Hz})$ and beta $(13-25 \mathrm{~Hz})$.

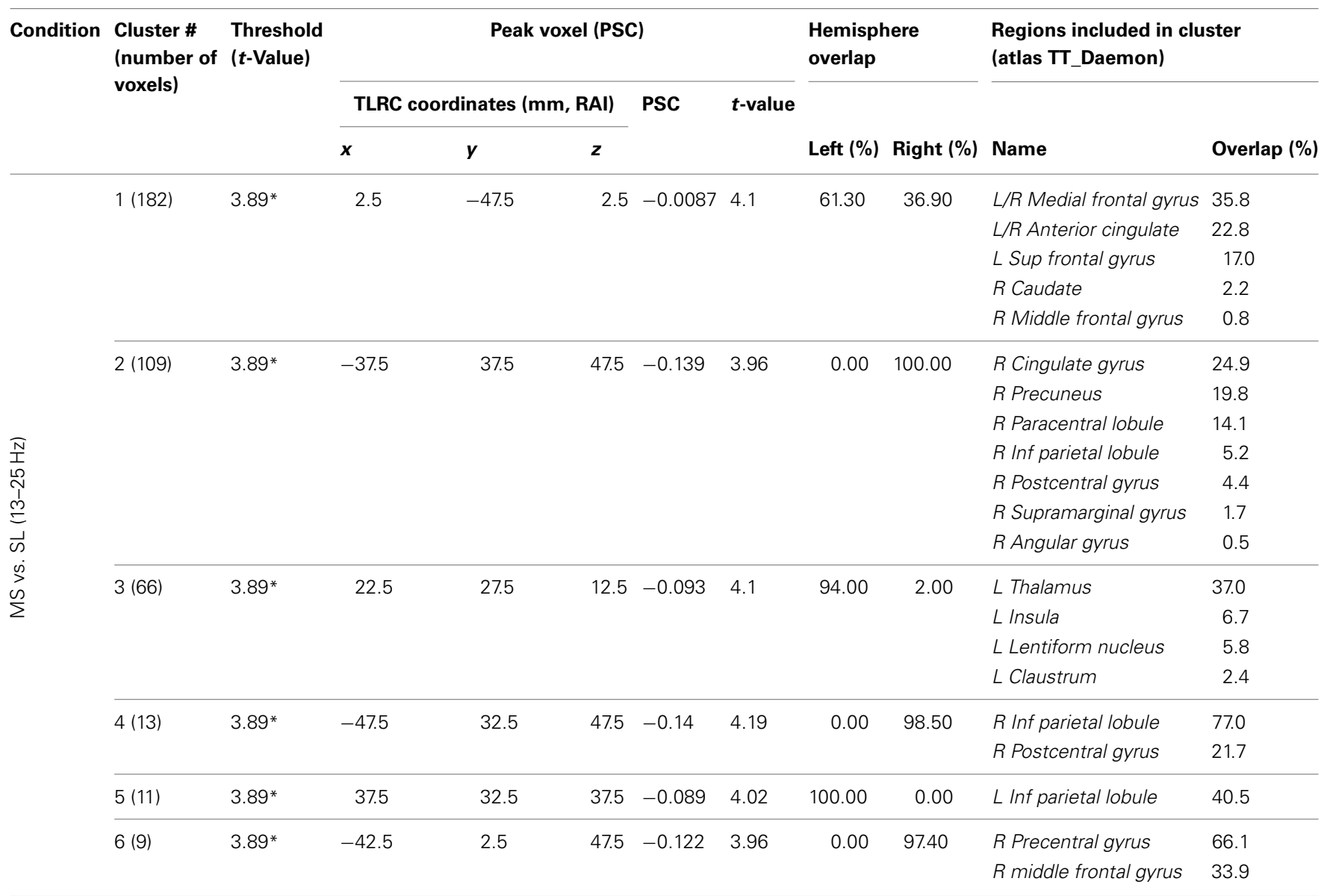

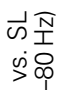

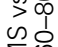 \\ $\sum \underline{\Theta}$}

No significant clusters

Information supplied includes number of voxels in each cluster, thresholds, peak voxel characteristics, hemispheric overlap, and brain regions included in the cluster. The Afni supplied TT Daemon atlas was used. Due to poor resolution and signal leakage to non-brain regions, overlap percentages do not always add up to $100 \%$. ${ }^{*} p<0.0025$ (corrected).

activity. As existing MEG studies of the self are either eventrelated studies (Walla et al., 2007) or connectivity studies (Lou et al., 2010b), the present study is the first to directly bridge fMRI BOLD and frequency-dependent MEG power results in the context of self-referential processing. The robust and extensive mPFC decreased gamma-power in MS relative to NS provide further evidence regarding the neural underpinning of the BOLD fMRI results, but also, importantly, anchor the results acquired through MEG to the main fMRI body of literature.

In addition to the reduced mPFC gamma oscillations, NS attenuation was also marked by a dramatic reduction of negative and mixed (both positive and negative) emotions: from 10 participants reporting such emotions in NS to only 1 in MS and SL, respectively. These are in alignment with findings directly associating increased midline activity in DMN regions to self-related emotionality (Northoff et al., 2009; Wiebking et al., 2011). As the link between increased self-focus, mPFC activity, and mood and anxiety disorders has been previously established (for reviews see Ressler and Mayberg, 2007; Lemogne et al., 2012), the present findings supports the notion that approaching self-experience through a more present-centered focus may be critical to human well-being (Davidson, 2004). A similar conclusion was reached by Killingsworth and Gilbert (2010) who showed, based on a largescale web-based experience sampling survey, that a wandering mind (dominating over $46 \%$ of waking experience) is less happy than a mind focused on what it is doing-regardless of the valence of the activity being engaged.

\section{MEDIAL AND LATERAL PARIETAL BETA-BAND OSCILLATORY ACTIVITY MEDIATE MS PROCESSING}

As mentioned, the MS network evidencing beta-band power attenuation (MS vs. SL) included posterior medial and lateral parietal regions (Figure 5), which were not part of the NS network (in both beta and gamma). The IPL and right precuneus 


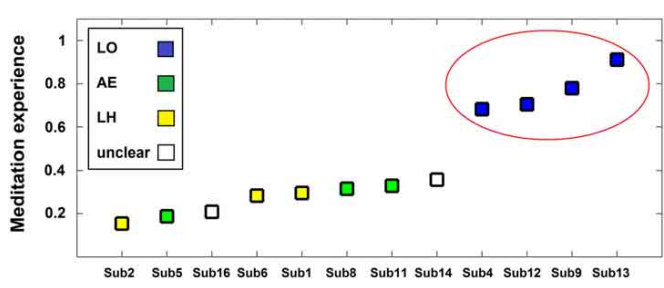

FIGURE 6 | Phenomenological categories and meditative expertise chart. Participants ( $x$-axis) are plotted as a function of meditative expertise ( $y$-axis) from least to most -experienced. The meditation experience measure is a normalized (0-1) measure incorporating both years and hours of meditation practice. Colors indicate phenomenological category of participants' SL description (blue $=\mathrm{LO}$ [Lack-of-ownership], green $=\mathrm{AE}$ [Altered-experience], yellow $=\mathrm{LH}$ [Less-happening], white $=$ unclear). Note the increase in meditative expertise for the LO group (circled in red).

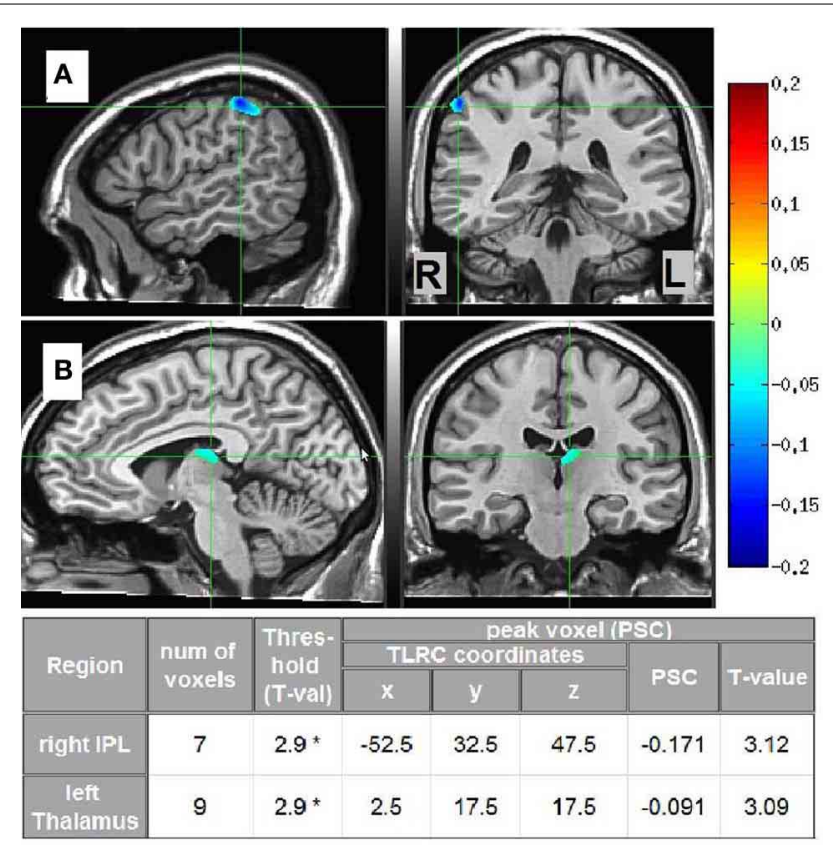

FIGURE 7 | LO source estimates. Sagittal and coronal views of significant $\left({ }^{*} p<0.02\right.$, corrected) LO source estimates $(n=4)$ relative to the other participants ( $n=6$, not including "unclear" category), overlayed on the Colin template. Crosshairs are in (A) on the right IPL; and in (B) on the left dorsomedial thalamus. The table provides Talairach coordinates, PSC, and other cluster details.

have been found to be involved in the mediation of agency (Farrer and Frith, 2002; Farrer et al., 2003; Nahab et al., 2011), in differentiating third- and first-person perspectives (Ruby and Decety, 2001; Vogeley and Fink, 2003; Vogeley et al., 2004), and in selfother discrimination (Uddin et al., 2006, 2007). The works of Olaf Blanke and colleagues (reviewed in Blanke, 2012), summarizing extensive neuroimaging and neurological data, highlight the role of right-hemisphere-dominated lateral parietal regions in mediating the most basic aspects of self-consciousness. Damasio (1999, 2010) argues that medial parietal regions are specifically involved in MS and not in NS (parallel to Damasio's core and extended selves, respectively). Laureys et al. (1999, 2004) show impaired PCC, precuneus, parieto-temporal, and prefrontal function in vegetative state patients, and suggest that it is the PCC/precuneus that distinguishes vegetative from minimally conscious patients. Using transcranial magnetic stimulation, Kwan et al. (2007) and Luber et al. (2012) established a causal role for the mPFC, but not the precuneus and right IPL in self-evaluation, while Lou et al. (2010a) showed the causal role of the IPL but not the mPFC in self-specific processes. Finally, Philippi et al. (2012) describe a patient with preserved self-awareness, recognition and agency, but an impaired autobiographical self, following extensive bilateral damage to the insula, ACC and $\mathrm{mPFC}$, with medial parietal regions left intact. Together, and in line with the present findings, a strong case can be made for dissociating parietal from prefrontal regions in regard to self-reference, linking the former with MS processing.

The main finding of the present study is the beta-band network underlying MS processing, clearly dissociable in the frequency domain from the well-documented gamma-frequency network underlying NS. This finding is not surprising when considering the related literature. The basic awareness of self and others has been most often studied within the context of the sense of agency, with two main theories attempting to account for it. The first of these is the classic or extended versions of the "comparator model" or "central monitoring theory" (Frith, 1992; Synofzik et al., 2008), which posit self-awareness to hinge on to motor optimization and control networks. The second theory is of action simulation or "mirror neurons" (reviewed in Sinigaglia and Rizzolatti, 2011), which claims that attributing actions to one's self or to others hinges on our capacity to represent action as our own motor possibilities. What is shared by both accounts is that they understand minimal self-awareness to be embodied within, or mapped onto, motor systems. Numerous studies in animals and humans, including MEG, implicate largescale beta band fronto-parietal oscillatory networks in sensorimotor decision-making, motor planning, and motor detection (reviewed in Siegel et al., 2012). While the sense of agency has not yet been empirically tied to a specific frequency band, mirror neuron effects have been shown to occur predominantly in the beta band in MEG studies (Muthukumaraswamy and Singh, 2008). Thus, as minimal self-awareness is theorized to hinge on motorrelated networks which manifest predominantly in the beta band, the logical frequency band to host MS representations is, in fact, the beta band.

\section{MS AS AN EARLY PRE-REFLECTIVE PROCESS INHERENT TO NS PROCESSING}

As mentioned in the introduction, some form of self-specifying minimal processing is in operation also during NS, accounting for narrative representations experienced as our representations. The pre-reflective nature of MS, and on the other hand, the reflective nature of NS, suggest that when self-related stimuli appear, MS processing will begin earlier than NS. While the present design does not reveal the temporal unfolding of MS vs. NS processing, there are a number of studies which may link the present findings to the time domain. The EEG-LORETA language-based (trait adjectives in reference to self, "I," or a close friend, "he/she") 
event-related study (Esslen et al., 2008) is particularly interesting, as it not only distinguishes, in line with the present and other findings (Zysset et al., 2003; Northoff et al., 2006; Schneider et al., 2008), the dorsal and ventral mPFC as differentially involved in reflective vs. pre-reflective self processing, but also determines their activation time-course. In the pre-reflective self condition, both the ventral mPFC and the insula were activated as early as 134-170 ms post stimulus, while differential dorsal mPFC activation in self vs. other -reference was only found when averaging over the whole time-course (700 ms). These temporal distinctions are upheld by a single MEG sensor-level study of self-awareness found in the literature (Walla et al., 2007). This event-related study, also language-based, examined encoding effects of the German language equivalents of "a," "his" and "mine," assumed to reflect different levels of self representation. The results indicated early (200-400 ms) and late (500-800 ms) time window effects. The 2D topography of the early time window reveals differential activity in posterior central electrodes (and in a few prefrontal ones), very similar to the $13-25 \mathrm{~Hz}$ beta-band 2D scalp map (Figure 3). Walla et al. interpret the early window effect as indicating a stage when the perceptual object, here a word, has not yet been branded as self/non-self, or in other words, a pre-MS stage. In contrast, the $2 \mathrm{D}$ representation of the late time window bears striking similarity to the $60-80 \mathrm{~Hz}$ high-gamma $2 \mathrm{D}$ scalp map presented in Figure 3 (frontal left activity). The similarity between the 2D cortical maps of MS and the early window, and NS and the later time window, together with the ventral vs. dorsal mPFC differential activation which holds both in terms of temporality (early vs. late time windows) and in terms of self processing mode (MS vs. NS), argue in favor of MS reflecting an early process inherent to the cognition of NS processing.

\section{THE NEUROPHENOMENOLOGY OF MINDFULNESS-INDUCED SELFLESSNESS}

Phenomenology played a double role in the present study, guiding both its design as well as data analysis. Regarding design, this study was inspired by "front-loading phenomenological insights into experimental design" (Gallagher and Sørensen, 2006). Specifically, and like other studies (Hasenkamp et al., 2012), mindfulness was employed in the spirit expressed by Varela et al. (1991) as a "... disciplined perspective on human experience that can enlarge the domain of cognitive science to include direct experience ..." (p. 33). Requesting long-term mindfulness practitioners to produce in laboratory settings the state of SL allowed a unique view of the neural correlates specific to the "minimal" aspect of momentary experience, rendering these aspects of human experience scientifically tractable (Lutz et al., 2007).

Regarding data analysis, collecting first-person descriptions of the SL experience allowed grouping the data into three distinct phenomenological categories (Table 1): AE descriptions indicated an altered spatial/sensual perspective of self experience, while $\mathrm{LH}$ descriptions indicated an attenuation of experience/r. LO descriptions, on the other hand, produced by participants cultured by a qualitatively greater meditation experience (Figure 6), indicated an attenuation of the agentive/ownership aspects accompanying experience. Despite the different phenomenological descriptions, all of the participants reported similar high rates of success and stability in all the tasks (including SL) relative to their past experiences (see section 3.1). This discrepancy can be interpreted as indicating a diminished MS experience for all participants, but diminished through different strategies and accompanied by distinct phenomenological experiences. In particular, the more experienced LO group is interesting as their descriptions indicate a specific subtraction of agency/ownership from momentary experience. This distinct phenomenology was then tied to a distinct neural signature: a further attenuation of beta-band power (relative to the AE and LH groups) in the left dorsomedial thalamus and right IPL (Figure 7).

Subcortical regions have only recently begun to be incorporated into theories of self-awareness (see Northoff and Panksepp, 2008; Damasio, 2010 and Christoff et al., 2011). The reported suppressed beta power in the dorsomedial thalamus support these researchers' hypotheses regarding the crucial involvement of subcortical circuits in the mediation of primal mammalian core processes tagging phenomena as self/not-self, which then feed into higher MS cortical representations. On the cortical level, the right inferior parietal sulcus has been highlighted as a region integrating multisensory bodily signals and reflecting the conscious experience of being an "I," a spatially localized entity corresponding to first-person perspective and identity (Ionta et al., 2011; Blanke, 2012). The IPL has also been hypothesized as a key region responsible for the sense of agency and subjective sense of control (e.g., Farrer et al., 2008; Nahab et al., 2011; Haggard and Chambon, 2012). Along with these studies, the present findings support the role of this region in reflecting one of the most astonishing features of the human mind, the subjective "self as I" aspect of conscious experience, and put forth the hypothesis-to be examined by subsequent research-that it is mediated specifically within the beta band.

\section{STUDY LIMITATIONS}

One limitation of the study concerns its unique participants. We acknowledge a potential lack of generalizability to non-vipassana and non-meditator general populations, in particular regarding the state of SL, which is an experience cultured by meditation practice and comprehensible from a Buddhist, but perhaps not Western, point of view (but see Metzinger, 2003). Another limitation regards the small sample of participants, especially in the neurophenomenological analysis, which yielded very small groups. Thus, the results reported here warrant replication in a larger group and in other meditative traditions. In addition, the reported phenomenological analysis is rudimentary in nature. This is partly due to the experimental conditions of interviewing participants via intercom between tasks, but partly also to the exploratory nature of the advent of translating phenomenological insights of long-established contemplative traditions into current neurocognitive terms. Future studies can build on these preliminary results and develop more sophisticated phenomenological characterizations of self and selfless modes of awareness using more rigorous qualitative/phenomenological analysis methods.

\section{CONCLUDING REMARKS}

The present study highlighted the role of frequency-dependent networks, dissociable in the frequency domain but partially 
overlapping in brain topography, in supporting different modes of self-processing. These results emphasize the unique contribution of MEG to the neuroimaging self-awareness literature. In addition, the present study illustrated the utility of combining first-person reports, neuroimaging, and Buddhist-inspired mind training for scientifically characterizing selflessness. Indeed, a non-trivial outcome of the present study is that long-term mindfulness meditators are actually able, under experimental conditions, to successfully produce and steadily hold a selfless mode of awareness. This state of mind, which is alien to normal non-pathological conscious experience and which has not been previously scientifically documented and neurocognitively mapped, allows a unique glance at the neural

\section{REFERENCES}

Andrews-Hanna, J. R., Reidler, J. S., Sepulcre, J., Poulin, R., and Buckner, R. L. (2010). Functional-anatomic fractionation of the brain's default network. Neuron 65, 550-562. doi: 10.1016/j.neuron.2010.02.005

Austin, J. H. (2000). Consciousness evolves when the self dissolves. J. Conscious. Stud. 7, 209-230.

Berkovich-Ohana, A., Glicksohn, J., and Goldstein, A. (2012). Mindfulness-induced changes in gamma band activity - implications for the default mode network, self-reference and attention. Clin. Neurophysiol. 123, 700-710. doi: 10.1016/j.clinph.2011.07.048

Blanke, O. (2012). Multisensory brain mechanisms of bodily selfconsciousness. Nat. Neurosci. 13, 556-571. doi: 10.1038/nrn3292

Brefczynski-Lewis, J. A., Lutz, A., Schaefer, H. S., Levinson, D. B., and Davidson, R. J. (2007). Neural correlates of attentional expertise in long-term meditation practitioners. Proc. Natl. Acad. Sci. U.S.A. 104, 11483-11488. doi: 10.1073/pnas.0606552104

Brewer, J. A., Worhunsky, P. D., Gray, J. R., Tang, Y.-Y., Weber, J., and Kober, H. (2011). Meditation experience is associated with differences in default mode network activity and connectivity. Proc. Natl. Acad. Sci. U.S.A. 108, 20254-20259. doi: 10.1073/pnas.1112029108

Brookes, M. J., Hale, J. R., Zumer, J. M., Stevenson, C. M., Francis, S. T., Barnes, G. R., et al. (2011). Measuring functional connectivity using MEG: methodology and comparison with fcMRI. Neuroimage 56, 1082-1104. doi: 10.1016/j.neuroimage.2011.02.054

Brookes, M. J., Vrba, J., Robinson, S. E., Stevenson, C. M., Peters, A. M., Barnes, G. R., et al. (2008). Optimising experimental design for MEG beamformer imaging.
Neuroimage 39, 1788-1802. doi: 10.1016/j.neuroimage.2007.09.050

Buckner, R. L., Andrews-Hanna, J. R., and Schacter, D. L. (2008). The brain's default network. Ann. N.Y. Acad. Sci. 1124: 1-38. doi:

Cahn, B. R., and Polich, J. (2006). Meditation states and traits: EEG, ERP, and neuroimaging studies. Psychol. Bull. 132, 180-211. doi: 10.1037/0033-2909.132.2.180

Chambers, R., Gullone, E., and Allen, N. B. (2009). Mindful emotion regulation: an integrative review. Clin. Psychol. Rev. 29, 560-572. doi: 10.1016/j.cpr.2009. 06.005

Chiesa, A., and Serretti, A. (2010). A systematic review of neurobiological and clinical features of mindfulness meditations. Psychol. Med. 40, 1239-1252. doi: 10.1017/S0033291709991747

Chiesa, A., Calati, R., and Serretti, A. (2011). Does mindfulness training improve cognitive abilities? A systematic review of neuropsychological findings. Clin. Psychol. Rev. 31, 449-464. doi: 10.1016/j.cpr.2010.11.003

Christoff, K., Cosmelli, D., Legrand, Specifying the self for cognitive neuroscience. Trends Cogn. Sci. 15, 104-112. doi: 10.1016/j.tics.2011.01.001

Christoff, K., Gordon, A. M., Smallwood, J., Smith, R., and Schooler, J. W. (2009). Experience sampling during fMRI reveals default network and executive system contributions to mind wandering. Proc. Natl. Acad. Sci. U.S.A. 106, 8719-8724. doi: 10.1073/pnas.0900234106

Claus, S., Velis, D., Lopes da Silva, F. H., Viergever, M. A., and Kalitzin, S. (2012). High frequency spectral components after secobarbital: the contribution of muscular 10.1196/annals.1440.011 D., and Thompson, E. (2011).

underpinnings of the more subtle and basic processes of selfawareness.

\section{ACKNOWLEDGMENTS}

We thank Prof. Rafael Malach for the anatomical data from his lab, and Dr. Stephen Fulder for his assistance in designing the experiment. This research was supported by the Mind and Life Institute, Francisco J. Varela Research Award 2012-VarelaBerkovich, and by a grant from the Bial Foundation (27/10). This paper is based on a thesis written by the first author and supervised by two of the authors (Joseph Glicksohn and Abraham Goldstein), submitted to Bar-Ilan University in partial fulfillment of the requirements toward an M.Sc. degree.

origin-a study with MEG/EEG. Epilepsy Res. 100, 132-141. doi: 10.1016/j.eplepsyres.2012.02.002

Dalai Lama, XIV. (1991). Path to Bliss. Ithaca, NY: Snow Lion.

Damasio, A., Damasio, H., and Tranel, D. (2012). Persistence of feelings and sentience after bilateral damage of the insula. Cereb. Cortex 23, 833-846. doi: $10.1093 /$ cercor/bhs077

Damasio, A. R. (1999). The Feeling of What Happens: Body and Emotion in the Making of Consciousness. New York, NY: Harcourt Inc.

Damasio, A. R. (2010). When Self Comes to Mind. New York, NY: Pantheon Books.

D'Argembeau, A., Collette, F., Van der Linden, M., Laureys, S., Del Fiore, G., Deguelrdre, C., et al. (2005). Self-referential reflective activity and its relationship with rest: a PET study. Neuroimage 25, 616-624. doi: 10.1016/j.neuroimage.2004.11.048

David, N., Newen, A., and Vogeley, K. (2008). The "sense of agency" and its underlying cognitive and neural mechanisms. Conscious. Cogn. 17, 523-534. doi: 10.1016/j.concog.2008.03.004

Davidson, R. J. (2004). Well-being and affective style: neural substrates and biobehavioural correlates. Philos. Trans. R. Soc. Lond. B Biol. Sci. 359, 1395-1411. doi: 10.1098/rstb.2004. 1510

Davidson, R. J., and Lutz, A. (2008). Buddha's brain: neuroplasticity and meditation. IEEE Signal Process. Mag. 25, 171-176. doi: 10.1109/MSP.2008.4431873

Dreyfus, G., and Thompson, E. (2007). "Asian perspectives: Indian theories of mind," in The Cambridge Handbook of Consciousness, eds E. Thompson, P. D. Zelazo, and M. Moscovitch (Cambridge: Cambridge University Press), 89-114. doi: 10.1017/ CBO9780511816789.006
Ekman, P., Davidson, R. J., Ricard, M., and Wallace, A. (2005). Buddhist and psychological perspectives on emotions and well-being. Curr. Dir. Psychol. Sci. 14, 59-63. doi: 10.1111/j.0963-7214.2005.00335.x

Engler, J. (2003). "Being somebody and being nobody: a reexamination of the understanding of self in psychoanalysis and Buddhism," in Psychoanalysis and Buddhism, ed J. D. Safran (Somerville, MA: Wisdom Publications), 35-100.

Esslen, E., Metzler, S., PascualMarqui, R., and Jancke, L. (2008). Pre-reflective and reflective selfreference: a spatiotemporal EEG analysis. Neuroimage 42, 437-449. doi: 10.1016/j.neuroimage.2008. 01.060

Farb, N. A. S., Segal, Z. V., Mayberg, H., Bean, J., McKeon, D., Fatima, Z., et al. (2007). Attending to the present: mindfulness meditation reveals distinct neural modes of self-reference. Soc. Cogn. Affect. Neurosci. 2, 313-322. doi: 10.1093/scan/nsm030

Farrer, C., Franck, N., Georgieff, N., Frith, C. D., Decety, J., and Jeannerod, M. (2003). Modulating the experience of agency: a positron emission tomography study. Neuroimage 18, 324-333. doi: 10.1016/S1053-8119(02)00041-1

Farrer, C., Frey, S. H., Van Horn, J. D., Tunik, E., Turk, D., Inati, S., et al. (2008). The angular gyrus computes action awareness representations. Cereb. Cortex 18, 254-261. doi: 10.1093/cercor/bhm050

Farrer, C., and Frith, C. D. (2002). Experiencing oneself vs another person as being the cause of an action: the neural correlates of the experience of agency. Neuroimage 15, 596-603. doi: 10.1006/nimg.2001.1009

Forman, S. D., Cohen, J. D., Fitzgerald, M., Eddy, W. F., Mintun, M. A., and Noll, D. C. (1995). Improved 
assessment of significant activation in functional magnetic resonance imaging (fMRI): use of a cluster-size threshold. Magn. Reson. Med. 33, 636-647. doi: 10.1002/mrm. 1910330508

Frith, C. D. (1992). The Cognitive Neuropsychology of Schizophrenia. Hillsdale, NJ: Erlbaum.

Froeliger, B., Garland, E. L., Kozink, R. V., Modlin, L. A., Chen, N.-K., McClernon, F. J., et al. (2012). Meditation-state functional connectivity (msfc): strengthening of the dorsal attention network and beyond. Evid. Based Complement. Alternat. Med. 2012, 680407. doi: $10.1155 / 2012 / 680407$

Gallagher, S. (2000). Philosophical conceptions of the self: implications for cognitive science. Trends Cogn. Sci. 4, 14-21. doi: 10.1016/S13646613(99)01417-5

Gallagher, S. (2002). Experimenting with introspection. Trends Cogn. Sci. 6, 374-375. doi: 10.1016/S13646613(02)01979-4

Gallagher, S. (2004). Neurocognitive models of schizophrenia: a neurophenomenological critique. Psychopathology 37, 8-19. doi: 10.1159/000077014

Gallagher, S., and Sørensen, J. B. (2006). Experimenting with phenomenology. Conscious. Cogn. 15, 119-134. doi: 10.1016/j.concog. 2005.03.002

Gardiner, J. M. (2001). Episodic memory and autonoetic consciousness: a first-person approach. Philos. Trans. R. Soc. Lond. B Biol. Sci. 356, 1351-1361. doi: 10.1098/rstb.2001.0955

Goleman, D. (1995). Emotional Intelligence. New York, NY: Bantam Books.

Gusnard, D. A., Akbudak, E., Shulman, G. L., and Raichle, M. E. (2001). Medial prefrontal cortex and self-referential mental activity: relation to a default mode of brain function. Proc. Natl. Acad. Sci. U.S.A. 98, 4259-4264. doi: 10.1073/pnas.071043098

Gusnard, D. A., and Raichle, M. E. (2001). Searching for a baseline: functional imaging and the resting human brain. Nat. Rev. Neurosci. 2, 685-694. doi: 10.1038/35094500

Haggard, P., and Chambon, V. (2012). Sense of agency. Curr. Biol. 22, 390-392. doi: 10.1016/j.cub.2012. 02.040

Hansen, P., Kringelbach, M., and Salmelin, R. (eds.). (2010). MEG: An Introduction to Methods. New York, NY: Oxford University Press. doi: 10.1093/acprof:oso/ 9780195307238.001.0001
Hart, W. (1987). The Art of Living: Vipassana Meditation. San Francisco, CA: HarperOne.

Hasenkamp, W., and Barsalou, L. W. (2012). Effects of meditation experience on functional connectivity of distributed brain networks. Front. Hum. Neurosci. 6:38. doi: 10.3389/fnhum.2012.00038

Hasenkamp, W., Wilson-Mendenhall, C. D., Duncan, E., and Barsalou, L. W. (2012). Mind wandering and attention during focused meditation: a fine-grained temporal analysis of fluctuating cognitive states. Neuroimage 59, 750-760. doi: 10.1016/j.neuroimage.2011.07.008

Hölzel, B. K., Carmody, J., Vangel, M., Congleton, C., Yerramsetti, S. M., Gard, T., et al. (2011a). Mindfulness practice leads to increases in regional brain gray matter density. Psychiatry Res.191, 36-43. doi: 10.1016/j.pscychresns.2010.08.006

Hölzel, B. K., Lazar, S. W., Gard, T., Schuman-Olivier, Z., Vago, D. R., and Ott, U. (2011b). How does mindfulness meditation work? Proposing mechanisms of action from a conceptual and neural perspective. Perspect. Psychol. Sci. 6, 537-559. doi: 10.1177/1745691611419671

Hölzel, B. K., Ott, U., Gard, T., Hempel, H., Weygandt, M., Morgen, K., et al. (2008). Investigation of mindfulness meditation practitioners with voxel-based morphometry. Soc. Cogn. Affect. Neurosci. 3, 55-61. doi: 10.1093/scan/ nsm038

Ionta, S., Heydrich, L., Lenggenhager, B., Mouthon, M., Fornari, E., Chapuis, D., et al. (2011). Multisensory mechanisms in temporo-parietal cortex support self-location and first-person perspective. Neuron 70, 363-374. doi: 10.1016/j.neuron.2011.03.009

Ives-Deliperi, V. L., Solms, M., and Meintjes, E. M. (2011). The neural substrates of mindfulness: an fMRI investigation. Soc. Neurosci. 6, 231-242. doi: 10.1080/17470919.2010.513495

Jack, A. I., and Roepstorff, A. (2002). Introspection and cognitive brain mapping: from stimulus-response to script-report. Trends Cogn. Sci. 6, 333-339. doi: 10.1016/S13646613(02)01941-1

James, W. (1890). The Principles of Psychology. New York, NY: Henry-Holt and Company. doi: 10.1037/11059-000

Jerbi, K., Vidal, J. R., Ossandón, T., Dalal, S. S., Jung, J., Hoffmann, D., et al. (2010). Exploring the electrophysiological correlates of the default-mode network with intracerebral EEG. Front. Syst. Neurosci. 4:27. doi: 10.3389/fnsys.2010.00027

Jung, T. P., Makeig, S., Westerfield, M., Townsend, J., Courchesne, E., and Sejnowski, T. J. (2000). Removal of eye activity artifacts from visual event-related potentials in normal and clinical subjects. Clin. Neurophysiol. 111, 1745-1758. doi: 10.1016/S1388-2457(00)00386-2

Kabat-Zinn, J. (1982). An outpatient program in behavioral medicine for chronic pain patients based on the practice of mindfulness meditation: theoretical considerations and preliminary results. Gen. Hosp. Psychiatry 4, 33-47. doi: 10.1016/0163-8343(82)90026-3

Kabat-Zinn, J. (1990). Full Catastrophe Living: Using the Wisdom of Your Body and Mind to Face Stress, Pain, and Illness. New York, NY: Delta.

Kabat-Zinn, J., Massion, A. O., Kristeller, J., Peterson, L. G., Fletcher, K. E., Pbert, L., et al. (1992). Effectiveness of a meditation-based stress reduction program in the treatment of anxiety disorders. Am. J. Psychiatry 149, 936-943.

Kerr, C. E., Josyula, K., and Littenberg, R. (2011). Developing an observing attitude: an analysis of meditation diaries in an MBSR clinical trial. Clin. Psychol. Psychother. 18, 80-93. doi: 10.1002/cpp.700

Killingsworth, M. A., and Gilbert, D. T. (2010). A wandering mind is an unhappy mind. Science 330, 932. doi: $10.1126 /$ science. 1192439

Kim, H. (2012). A dual-subsystem model of the brain's default network: self-referential processing, memory retrieval processes, and autobiographical memory retrieval. Neuroimage 61, 966-977. doi: 10.1016/j.neuroimage.2012.03.025

Kwan, V. S., Barrios, V., Ganis, G., Gorman, J., Lange, C., Kumar, M., et al. (2007). Assessing the neural correlates of self-enhancement bias: a transcranial magnetic stimulation study. Exp. Brain Res. 182, 379-385. doi: 10.1007/s00221-007-0992-2

Laureys, S., Goldman, S., Phillips, C., Van Bogaert, P., Aerts, J., and Luxen, A. (1999). Impaired effective cortical connectivity in vegetative state. Neuroimage 9, 377-382. doi: 10.1006/nimg.1998.0414

Laureys, S., Owen, A. M., and Schiff, N. D. (2004). Brain function in coma, vegetative state, and related disorders. Lancet Neurol. 3, 537-546. doi: 10.1016/S1474-4422(04)00852-X

Lazar, S. W., Kerr, C. E., Wasserman, R. H., Gray, J. R., Greve, D. N., Treadway, M. T., et al. (2005).
Meditation experience is associated with increased cortical thickness. Neuroreport 16, 1893-1897. doi: 10.1097/01.wnr.0000186598. 66243.19

Legrand, D., and Ruby, P. (2009). What is self-specific? Theoretical investigation and critical review of neuroimaging results. Psychol. Rev. 116, 252-282. doi: 10.1037/a0014172

Lehmann, D., Faber, P. L., Tei, S., Pascual-Marqui, R. D., Milz, P., and Kochi, K. (2012). Reduced functional connectivity between cortical sources in five meditation traditions detected with lagged coherence using EEG tomography. Neuroimage 60, 1574-1586. doi: 10.1016/j.neuroimage.2012.01.042

Lemogne, C., Delaveau, P., Freton, M., Guionnet, S., and Fossati, P. (2012). Medial prefrontal cortex and the self in major depression. J. Affect. Disord. 136, e1-e11. doi: 10.1016/j.jad.2010.11.034

Lou, H. C., Gross, J., Biermann-Ruben, K., Kjaer, T. W., and Schnitzler, A. (2010b). Coherence in consciousness: paralimbic gamma synchrony of self-reference links conscious experiences. Hum. Brain Mapp. 31, 185-192. doi: 10.1002/hbm.20855

Lou, H. C., Luber, B., Stanford, A., and Lisanby, S. H. (2010a). Selfspecific processing in the default network: a single-pulse TMS study. Exp. Brain Res. 207, 27-38. doi: 10.1007/s00221-010-2425-x

Luber, B., Lou, H. C., Keenan, J. P., and Lisanby, S. H. (2012). Selfenhancement processing in the default network: a single-pulse TMS study. Exp. Brain Res. 223, 177-187. doi: 10.1007/s00221-0123249-7

Lutz, A., Dunne, J. D., and Davidson, R. J. (2007). "Meditation and the neuroscience of consciousness," in Cambridge Handbook of Consciousness, eds P. Zelazo, M. Moscovitch, and E. Thompson (New York, NY: Cambridge University Press), 499-555. doi: 10.1017/CBO9780511816789.020

Lutz, A., Slagter, H. A., Dunne, J. D., and Davidson, R. J. (2008). Attention regulation and monitoring in meditation. Trends Cogn. Sci. 12, 163-169. doi: 10.1016/j.tics.2008.01.005

Lutz, A., and Thompson, E. (2003). Neurophenomenology: integrating subjective experience and brain dynamics in the neuroscience of consciousness. J. Conscious. Stud. 10, 31-52.

Mantini, D., Perrucci, M. G., Del Gratta, C., Romani, G. L., and Corbetta, M. (2007). 
Electrophysiological signatures of resting state networks in the human brain. Proc. Natl. Acad. Sci. U.S.A. 104, 13170-13175. doi: 10.1073/pnas.0700668104

Maris, E., and Oostenveld, R. (2007). Nonparametric statistical testing of EEG- and MEG-data. J. Neurosci. Methods 164, 177-190. doi: 10.1016/j.jneumeth.2007.03.024

Mason, M. F., Norton, M. I., Van Horn, J. D., Wegner, D. M., Grafton, S. T., and Macrae, C. N. (2007). Wandering minds: the default network and stimulus-independent thought. Science 315, 393-395. doi: 10.1126/science.1131295

Metzinger, T. (2003). Being No One. The Self-Model Theory of Subjectivity. Cambridge: MIT Press.

Muthukumaraswamy, S. D. (2013). High-frequency brain activity and muscle artifacts in MEG/EEG: a review and recommendations. Front. Hum. Neurosci. 7:138. doi: 10.3389/fnhum.2013.00138

Muthukumaraswamy, S. D., and Singh, K. D. (2008). Modulation of the human mirror neuron system during cognitive activity. Psychophysiology 45, 896-905. doi: 10.1111/j.1469-8986.2008.00711.x

Nahab, F. B., Kundu, P., Gallea, C., Kakareka, J., Pursley, R., Pohida, T., et al. (2011). The neural processes underlying self-agency. Cereb. Cortex 21, 48-55. doi: 10.1093/cercor/bhq059

Neisser, U. (1988). Five kinds of selfknowledge. Philos. Psychol. 1, 35-59. doi: 10.1080/09515088808572924

Nichols, T. E., and Holmes, A. P. (2001). Nonparametric permutation tests for functional neuroimaging: a primer with examples. Hum. Brain Mapp. 15, 1-25. doi: 10.1002/hbm.1058

Nir, Y., Fisch, L., Mukamel, R., GelbardSagiv, H., Arieli, A., Fried, I., et al. (2007). Coupling between neuronal firing rate, gamma LFP, and BOLD fMRI is related to interneuronal correlations. Curr. Biol. 17, 1275-1285. doi: 10.1016/j.cub.2007.06.066

Northoff, G., Heinzel, A., de Greck, M., Bermpohl, F., Dobrowolny, H., and Panksepp, J. (2006). Self-referential processing in our brain-a metaanalysis of imaging studies on the self. Neuroimage 31, 440-457. doi: 10.1016/j.neuroimage.2005.12.002

Northoff, G., and Panksepp, J. (2008). The trans-species concept of self and the subcorticalcortical midline system. Trends Cogn. Sci. 12, 259-264. doi: 10.1016/j.tics.2008.04.007

Northoff, G., Qin, P., and Feinberg, T. E. (2011). Brain imaging of the self-conceptual, anatomical and methodological issues. Conscious. Cogn. 20, 52-63. doi: 10.1016/j.concog.2010.09.011

Northoff, G., Schneider, F., Rotte, M., Matthiae, C., Tempelmann, C., and Wiebking, C. (2009). Differential parametric modulation of self-relatedness and emotions in different brain regions. Hum. Brain Mapp. 30, 369-382. doi: 10.1002/hbm.20510

Nydahl, O. (2008). The Way Things Are: A Living Approach to Buddhism. UK: O Books.

Olendzki, A. (2010). Unlimiting Mind: The Radically Experiential Psychology of Buddhism. Somerville, MA: Wisdom Publications.

Oostenveld, R., Fries, P., Maris, E., and Schoffelen, J.-M. (2011). FieldTrip: open source software for advanced analysis of MEG, EEG, and invasive electrophysiological data. Comput. Intell. Neurosci. 2011, 156869. doi: 10.1155/2011/156869

Ossandón, T., Jerbi, K., Vidal, J. R., Bayle, D. J., Henaff, M. A., Jung, J., et al. (2011). Transient suppression of broadband gamma power in the default-mode network is correlated with task complexity and subject performance. J. Neurosci. 31, 14521-14530. doi: 10.1523/JNEUROSCI.2483-11.2011

Pagnoni, G., Cekic, M., and Guo, Y. (2008). "Thinking about NotThinking": neural correlates of conceptual processing during zen meditation. PLoS ONE 3:e3083. doi: 10.1371/journal.pone.0003083

Philippi, C. L., Feinstein, J. S., Khalsa, S. S., Damasio, A., Tranel, D., Landini, G., et al. (2012). Preserved self-awareness following extensive bilateral brain damage to the insula, anterior cingulate, and medial prefrontal cortices. PLOS ONE 7:e38413. doi: 10.1371/journal.pone.0038413

Qin, P., and Northoff, G. (2011). How is our self related to midline regions and the default-mode network? Neuroimage 57, 1221-1233. doi: 10.1016/j.neuroimage.2011.05.028

Raichle, M. E., MacLeod, A. M., Snyder, A. Z., Powers, W. J., Gusnard, D. A., and Shulman, G. L. (2001). A default mode of brain function. Proc. Natl. Acad. Sci. U.S.A. 98, 676-682. doi: 10.1073/pnas.98.2.676

Ramot, M., Fisch, L., Harel, M., Kipervasser, S., Andelman, F., Neufeld, M. Y., et al. (2012). A widely distributed spectral signature of task-negative electrocorticography responses revealed during a visuomotor task in the human cortex. J. Neurosci. 32, 10458-10469. doi: 10.1523/ JNEUROSCI.0877-12.2012

Ressler, K. J., and Mayberg, H. S. (2007). Targeting abnormal neural circuits in mood and anxiety disorders: from the laboratory to the clinic. Nat. Neurosci. 10, 1116-1124. doi: 10.1038/nn1944

Robinson, S. E., and Vrba, J. (1999). "Functional neuroimaging by synthetic aperture magnetometry," in Recent Advances in Biomagnetism: Proceedings From the 11th International Conference on Biomagnetism, eds T. Yoshimine, M. Kotani, S. Kuriki, H. Karibe and N. Nakasato (Sendai: Tokoku University Press), 302-305.

Roepstorff, A. (2001). Brains in scanners: an Umwelt of cognitive neuroscience. Semiotica 134, 747-765.

Ruby, P., and Decety, J. (2001). Effect of subjective perspective taking during simulation of action: a PET investigation of agency. Nat. Neurosci. 4, 546-550. doi: 10.1038/87510

Schneider, F., Bermpohl, F., Heinzel, A., Rotte, M., Walter, M., Tempelmann, C., et al. (2008). The resting brain and our self: self-relatedness modulates resting state neural activity in cortical midline structures. Neuroscience 157, 120-131. doi: 10.1016/j.neuro science.2008.08.014

Schooler, J. W. (2002). Re-representing consciousness: dissociations between experience and metaconsciousness. Trends Cogn. Sci. 6 339-344. doi: 10.1016/S1364-6613 (02)01949-6

Sekihara, K., Hild, K. E., and Nagarajan, S. S. (2006). A novel adaptive beamformer for MEG source reconstruction effective when large background brain activities exist. IEEE Trans. Biomed. Eng. 53, 1755-1764. doi: 10.1109/TBME 2006.878119

Siegel, M., Donner, T. H., and Engel, A. K. (2012). Spectral fingerprints of large-scale neuronal interactions. Nat. Rev. Neurosci. 13, 121-134. doi: 10.1038/nrn3137

Singh, K. D. (2012). Which "neural activity" do you mean? fMRI, MEG, oscillations and neurotransmitters. Neuroimage 62, 1121-1130. doi 10.1016/j.neuroimage.2012.01.028

Singh, K. D., Barnes, G. R., and Hillebrand, A. (2003). Group imaging of task-related changes in cortical synchronisation using nonparametric permutation testing. Neuroimage 19, 1589-1601. doi: 10.1016/S1053-8119(03)00249-0

Sinigaglia, C., and Rizzolatti, G. (2011). Through the looking glass: self and others. Conscious. Cogn. 20, 64-74. doi: 10.1016/j.concog.2010. 11.012

Sperduti, M., Delaveau, P., Fossati, P., and Nadel, J. (2011). Different brain structures related to selfand external- agency attribution: a brief review and meta-analysis. Brain Struct. Funct. 216, 151-157. doi: 10.1007/s00429-010-0298-1

Synofzik, M., Vosgerau, G., and Newen, A. (2008). Beyond the comparator model: a multifactorial two-step account of agency. Conscious. Cogn. 17, 219-239. doi: 10.1016/j.concog.2007.03.010

Tagini, A., and Raffone, A. (2010). The ' $\mathrm{I}$ ' and the ' $\mathrm{Me}$ ' in selfreferential awareness: a neurocognitive hypothesis. Cogn. Process. 11, 9-20. doi: 10.1007/s10339-0090336-1

Tal, I., and Abeles, M. (2013). Cleaning MEG artifacts by external cues. J. Neurosci. Methods 217, 31-38. doi: 10.1016/j.jneumeth.2013.04.002

Talairach, J., and Tournoux, P. (1988). Co-planar Stereotaxic Atlas of the Human Brain: 3-Dimensional Proportional System - An Approach to Cerebral Imaging. New York, NY: Thieme Medical Publishing.

Taylor, V. A., Daneault, V., Grant, J., Scavone, G., Breton, E., Roffe-Vidal, S., et al. (2013). Impact of meditation training on the default mode network during a restful state. Soc. Cogn. Affect. Neurosci. 8, 4-14. doi: $10.1093 /$ scan/nsr087

Uddin, L. Q., Iacoboni, M., Lange, C., and Keenan, J. P. (2007). The self and social cognition: the role of cortical midline structures and mirror neurons. Trends Cogn. Sci. 11, 153-157. doi: 10.1016/j.tics.2007.01.001

Uddin, L. Q., Molnar-Szakacs, I., Zaidel, E., and Iacoboni, M. (2006). rTMS to the right inferior parietal lobule disrupts self-other discrimination. Soc. Cogn. Affect. Neurosci. 1, 65-71. doi: 10.1093/scan/nsl003

Vago, R., and Silbersweig, D. A. (2012). Self-awareness, selfregulation, and self-transcendence (S-ART): a framework for understanding the neurobiological mechanisms of mindfulness. Front. Hum. Neurosci. 6:296. doi: 10.3389/fnhum.2012.00296

Varela, F. J., Thompson, E. T., and Rosch, E. (1991). The Embodied Mind: Cognitive Science and Human Experience. Boston, MA: MIT Press. Vogeley, K., and Fink, G. R. (2003). Neural correlates of the first-person-perspective. Trends Cogn. Sci. 7, 38-42. doi: 10.1016/S1364-6613(02)00003-7 
Vogeley, K., May, M., Ritzl, A., Falkai, P., Zilles, K., and Fink, G. R. (2004). Neural correlates of firstperson perspective as one constituent of human self consciousness. J. Cogn. Neurosci. 16, 817-827. doi: 10.1162/089892904970799

Walla, P., Greinerb, K., Dureggerb, C., Deecke, L., and Thurner, S. (2007). Self-awareness and the subconscious effect of personal pronouns on word encoding: a magnetoencephalography (MEG) study. Neuropsychologia 45, 796-809. doi: $\quad 10.1016 /$ j.neuropsychologia. 2006.08.017

Wallace, B. A. (2006). The Attention Revolution: Unlocking the Power of the Focused Mind. Boston, MA: Wisdom Publications.

Whitfield-Gabrieli, S., Moran, J. M., Nieto-Castañón, A., Triantafyllou, C., Saxe, R., and Gabrieli, J. D.
E. (2011). Associations and dissociations between default and self-reference networks in the human brain. Neuroimage 55, 225-232. doi: 10.1016/j.neuro image.2010.11.048

Wiebking, C., de Greck, M., Duncan, N. W., Heinzel, A., Tempelmann, C., and Northoff, G. (2011). Are emotions associated with activity during rest or interoception? An exploratory fMRI study in healthy subjects. Neurosci. Lett. 491, 87-92. doi: 10.1016/j.neulet.2011. 01.012.

Williams, J. M. G., and Kabat-Zinn, J. (2011). Mindfulness: diverse perspectives on its meaning, origins, and multiple applications at the intersection of science and dharma. Contemp. Buddhism 12, 1-18. doi: 10.1080/14639947.2011. 564811
Zimmermann, R., and Scharein, E. (2004). MEG and EEG show different sensitivity to myogenic artifacts. Neurol. Clin. Neurophysiol. 2004, 78.

Zysset, S., Huber, O., Samson, A., Fersti, E. C., and von Cramon, D. Y. (2003). Functional specialization within the anterior medial prefrontal cortex: a functional magnetic resonance imaging study with human subjects. Neurosci. Lett. 335, 183-186. doi 10.1016/S0304-3940(02)01196-5

Conflict of Interest Statement: The authors declare that the research was conducted in the absence of any commercial or financial relationships that could be construed as a potential conflict of interest.

Received: 17 April 2013; accepted: 29 August 2013; published online: 24 September 2013.
Citation: Dor-Ziderman Y, BerkovichOhana A, Glicksohn J and Goldstein A (2013) Mindfulness-induced selflessness: a MEG neurophenomenological study. Front. Hum. Neurosci. 7:582. doi: 10.3389/fnhum.2013.00582

This article was submitted to the journal Frontiers in Human Neuroscience. Copyright (c) 2013 Dor-Ziderman, Berkovich-Ohana, Glicksohn and Goldstein. This is an open-access article distributed under the terms of the Creative Commons Attribution License (CC BY). The use, distribution or reproduction in other forums is permitted, provided the original author(s) or licensor are credited and that the original publication in this journal is cited, in accordance with accepted academic practice. No use, distribution or reproduction is permitted which does not comply with these terms. 